\title{
Final Report for DOE Project
}

\section{High Throughput Screening of Nanostructured Hydrogen Storage Materials}

Principal Investigator:

Co-Principal Investigator:

Subcontracts:

\author{
Gang Chen (MIT) \\ Mildred S. Dresselhaus (MIT) \\ Costas P. Grigoropoulos (UC Berkeley) \\ Samuel S. Mao (UC Berkeley) \\ Xiaodong Xiang (Intematix Corporation) \\ Taofang Zeng (NC State University/MIT)
}

Period Covered: September 1, 2005 - October 31, 2009

Office of Sponsored Programs

Massachusetts Institute of Technology

77 Massachusetts Avenue

Cambridge, MA 02139

Award Number: DE-FG02-05ER46241

Approved Budget for the Period: $\$ 2,055,000$

Actual Cost Incurred to Date: $\$ 2,0555,000$

Amount of Unexpended: $\$ 0$ 


\section{Sum mary}

Hydrogen storage is the most challenging task for the hydrogen economy. We established a multidisciplinary research program for high throughput combinatorial synthesis and characterization of novel nanoporous and metastable complex hydrides, coupled to fundamental material studies including electronic, structural and kinetic transport modeling, and pump-probe experiments. Our research is based the concept of hybrid nanostructures that store hydrogen by a combination of chemi- and physorption: atomic hydrogen is stored in metastable hydrides while molecule hydrogen is stored in the nanometer pores of the hydrides. Metastable nanostructured hydride has been achieved by introducing structural and compositional disorders through high throughput elemental substitution/doping, catalyst addition, and nonequilibrium processing. Fast screening compatible with the combinatorial synthesis was achieved by combining $X$-ray structural characterization with the development of a laser-based microbalance. Manufacturing of nanoporous metahydrides that are identified as promising by the combinatorial synthesis has been explored along with the materials search.

\section{PROGRAM SCOPE}

The project aims at developing nanostructured metastable hydride materials that are capable of storing hydrogen with both chemisorption and physisorption mechanisms, with fast sorption and desorption kinetics, and good heat transfer characteristics. These goals are to be achieved through combining a high throughput combinatorial materials approach with fundamental studies to identify basic physical processes related to high capacity and fast kinetics. The following targets have been identified:

- Destabilize metal hydrides using nanostructures synthesized by laser-based physical deposition and sol-gel nanochemistry.

- Development of high throughput optical screening method for metal hydrides using combinatorial materials discovery principles.

- Development of nanoporous hydride materials with integrated chemisorption and physisorption through synthesis of nanocomposite materials.

- Development of models for the fundamental understanding of size effects on the thermodynamics, kinetics of hydrogen sorption and desorption, and heat transfer in nanostructured hydrogen storage materials.

Numerous results have been obtained through the studies of the program. The main results of are reported in the following orders: hydride films, combinatorial screening, catalyzed hydrides in porous matrix, and modeling of nanostructured hydrides. 


\section{Free-standing Nanoparticle Hydride Films}

Using magnesium-based metal hydrides, we performed proof-of-principle studies of freestanding hydride films, which provide a convenient platform for fundamental investigations of materials' hydrogen sorption-desorption characteristics. We successfully fabricated free-standing, nanoparticle metal hydride films sandwiched between two Pd catalyst capping layers of thickness of a few nanometers. As shown in Figure 1, the structure has been proven to be able to avoid oxidation of the constituent light metals, as well as offer a well-defined interface between the metal and the catalyst nanoparticles.

Magnesium hydride has been a favorite material for basic metal hydride research. Also, the high theoretical storage capacity of $7.6 \mathrm{wt} . \%$ for $\mathrm{MgH}_{2}$ coupled with the abundance, low cost, and light weight of magnesium makes it an attractive candidate for hydrogen storage. However, the slow kinetics of hydrogen sorption and desorption calls for the utilization of catalysts and nanostructuring in order to meet the requirements for on board vehicle storage [1]. The Mg-Pd system has also been widely studied, and a vast improvement in hydrogenation temperature has been observed on the $\mathrm{MgH}_{2}$ system in the presence of $\mathrm{Pd}$. Most studies are conducted by ball milling magnesium and palladium [2-4]. Some researchers have sputtered smooth thin films of magnesium and palladium [5,6], but few studies have been performed on free-standing films of magnesium and palladium. The lack of work on free-standing films is due to the difficulty involved in depositing and delaminating films of magnesium from a suitable substrate while avoiding oxidation, which can occur quite rapidly [7].
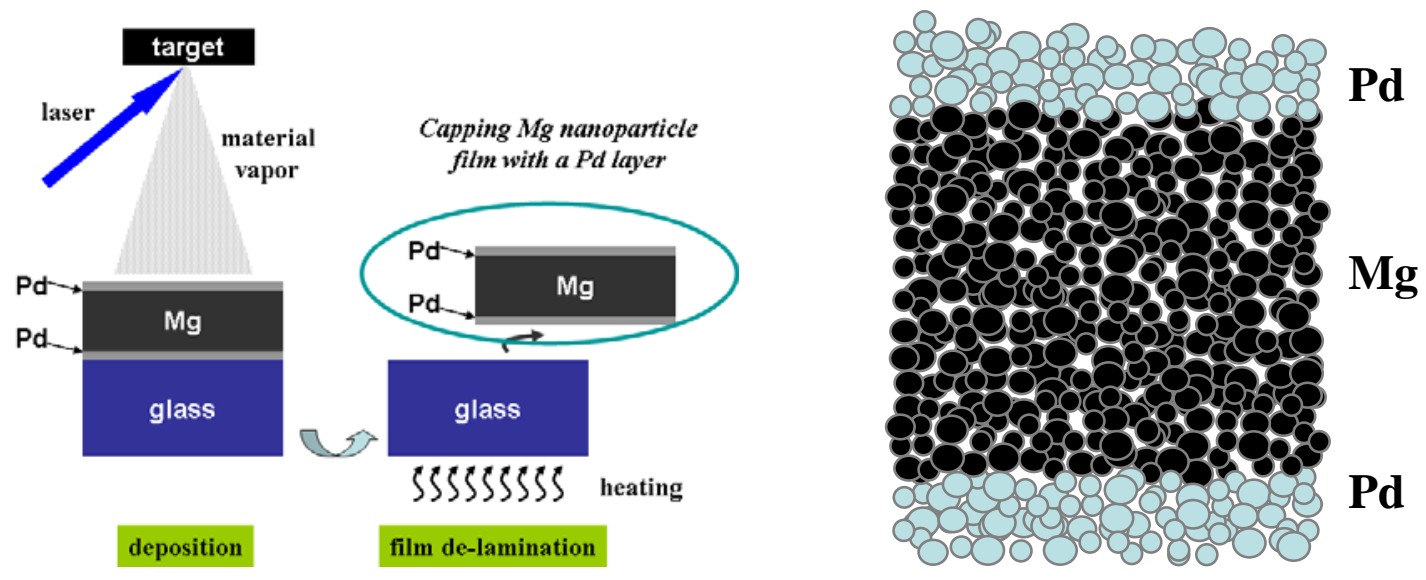

Figure 1. Left: schematic illustration of film deposition and removal of the film from substrate. Right: schematic illustration of a nanoparticle film (Mg film capped with $\mathrm{Pd}$ catalyst layers).

\subsection{Nanoparticle Size Control}

Fabrication of free-standing films consisting of layers of nanoparticle was achieved using laser-based deposition approach, which offers control over particle size distribution through the control of the many processing parameters. The most commonly exploited parameters for this purpose are the background pressure and gas species, while other parameters such as laser 
fluence, target to substrate distance, and substrate temperature are all interrelated and affect particle deposition size distributions.

A series of experiments were performed with a laser (248 $\mathrm{nm}$ wavelength) fluence of $4 \mathrm{~J} / \mathrm{cm}^{2}$ with a Si substrate at room temperature. A base pressure of $5 \times 10^{-7}$ Torr was reached before introduction of nitrogen as a background gas. A nitrogen flow rate was set so that a steady background pressure was attained. A range of pressures from the $1 \times 10^{-6}$ Torr to the 1 Torr range were tested. Particle size distributions were characterized using AFM, the results are shown in Figure 2. Initially, decreasing pressure results in increasing mean nanoparticle size; however, as the pressure continues to decrease, the mean nanoparticle size decreases as well. The trend of this graph implies that there are competing mechanisms at work in nanoparticle creation. Two interesting mechanisms to consider are the hydrodynamic affect of the background gas on the laser ablation plume, and the heat transfer effect due to the background gas. At very low pressures, the mean free path of the gas particles is much greater than the target to substrate distance, so the laser ablation plume is not affected by the surrounding gas and the plume can expand to a very large size. The plume undergoes an essentially free expansion and correspondingly cools. Once particles condensate, cooling can only occur due to radiation to their surroundings, as the likelihood of a collision with a gas molecule is small. The large size of the plume decreases the frequency at which particles collide, and agglomeration is limited. If the pressure is increased, plume expansion is retarded due to the ambient gas. Dependent upon laser fluence and the pressure, the plume may take different shapes and travel at different speeds. Once particles condensate, cooling may occur due to conduction, convection, radiation, and diffusion. These additional mechanisms may serve to increase the cooling rate after particle
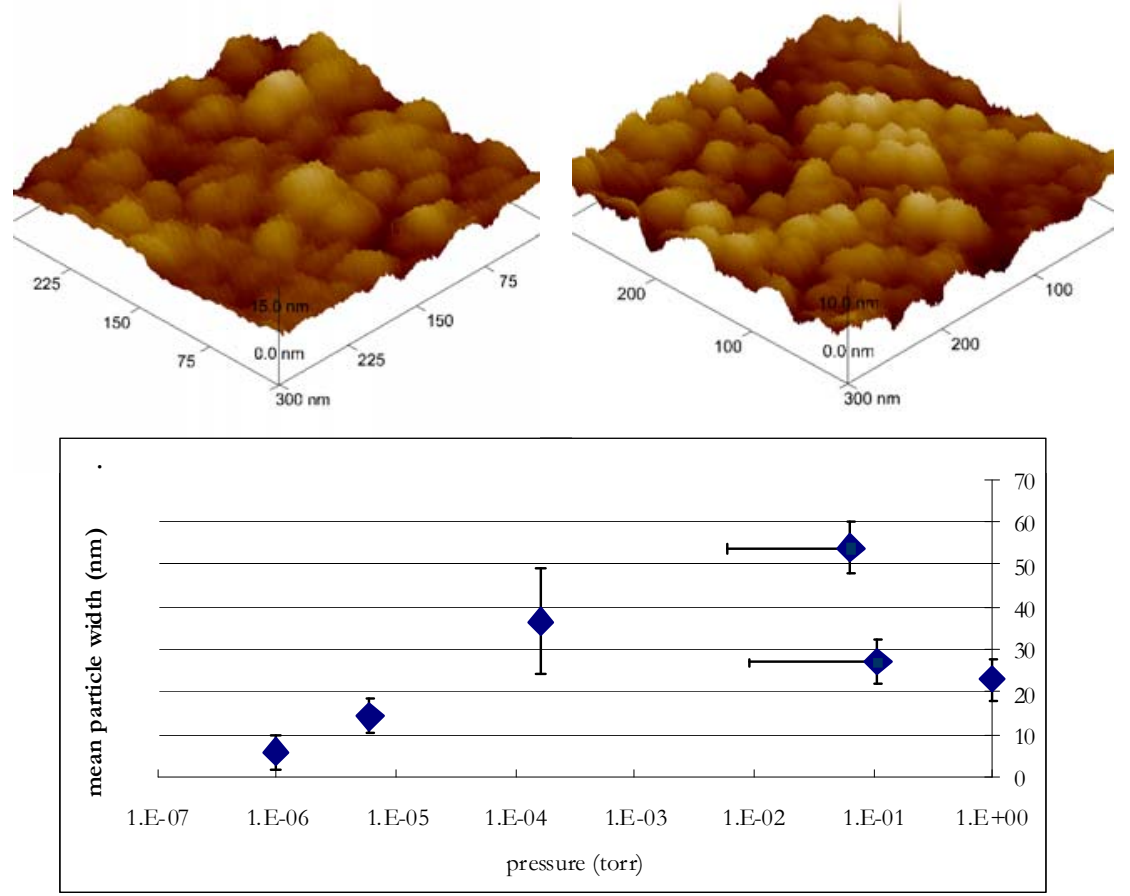

Figure 2. Measurement of nanoparticle mean diameter as a function of background pressure of the fabrication chamber. Two examples of AFM image of nanoparticle films are shown above the size-pressure plot. 
condensation; however, these mechanisms must compete with the fact that this ablation plume has been retarded, and is relatively dense compared to the low pressure ablation case. Therefore, agglomeration, and coalescence may play an increased role in determining the particle size distribution found. The competing mechanisms at work here are at least partially responsible for the trend seen in particle size distribution obtained at various background gas pressures. Other possible mechanisms such as plasma shielding at high background gas pressure may also contribute.

\subsection{X-ray Characterization before and after Hydrogenation}

The relatively high hydrogen sorption capacity, coupled with the poor kinetics of magnesium makes it a good candidate for fundamental studies using catalysts and alloys. Palladium and nickel are two of the most common candidates in this course of action. Both palladium and nickel serve as excellent catalysts for hydrogen dissociation. Nickel is a much cheaper alternative to palladium, and can be alloyed to form $\mathrm{Mg}_{2} \mathrm{Ni}$ as well as $\mathrm{MgNi}_{2}$. Hydrogenation of the first case can result in $\mathrm{Mg}_{2} \mathrm{NiH}_{4}$, which less stable than $\mathrm{MgH}_{2}$, therefore should release hydrogen at a lower temperature. The added weight of the nickel in the alloy decreases the overall theoretical hydrogen storage weight percentage from $7.6 \%$ to $3.4 \%$, which is too low for vehicle applications, but may be suitable for other applications [8-10].

XRD was performed to determine the crystallographic and film composition information of $\mathrm{Mg}_{\mathrm{x}} \mathrm{Ni}_{\mathrm{y}}$ films with Pd capping. Figure $3 \mathrm{a}$ and $3 \mathrm{~b}$ show typical XRD results before and after hydrogenation. The film was deposited on Si under a vacuum of $10^{-6} \mathrm{Torr}$, with a palladium and a target consisting of $\mathrm{Mg}_{2.8} \mathrm{Ni}$. In Figure 3a, broad peaks are observed due to the small crystallite size of nanoparticles, as well as the strain in the film. These peaks can be identified and correspond to $\mathrm{Mg}_{2} \mathrm{Ni}$ and $\mathrm{Pd}$. For hydrogenation process, films were loaded into the hydrogen testing chamber. The sample was allowed to degas over a period of 24 hours under vacuum before being heated up to $300 \mathrm{C}$ at 19 bar of hydrogen pressure. The sample was then cooled to room temperature and pumped to a vacuum before venting to air for material characterization. The decrease and disappear of the previously observed $\mathrm{Mg}_{2} \mathrm{Ni}$ peaks, as well as the formation of $\mathrm{MgH}_{2}$ and $\mathrm{Mg}_{2} \mathrm{NiH}_{4}$ indicate that the film was successfully loaded with hydrogen, as shown in Figure $3 b$.

\subsection{Hydrogen Storage Characterization of Hydride Films}

Both volumetric and gravimetric methods have been applied to measure materials' hydrogen storage characteristics. As an example, the weight-based testing procedure includes three basic steps: (1) pressure is varied and then held constant during sorption at a set point $\left(\mathrm{P}_{\mathrm{n}}\right)$; (2) weight data is acquired and analyzed in real time to determine the kinetic parameters and to predict the exact point of equilibrium hydrogen uptake $\left(E_{n}\right)$; and (3) data points are collected and plotted as an isotherm (as shown in Figure 4). For samples as small as $10 \mu \mathrm{g}$, a gravimetric apparatus based on a high sensitivity, digital recording microbalance capacity, and a special micro-dosing volumetric apparatus were applied. 

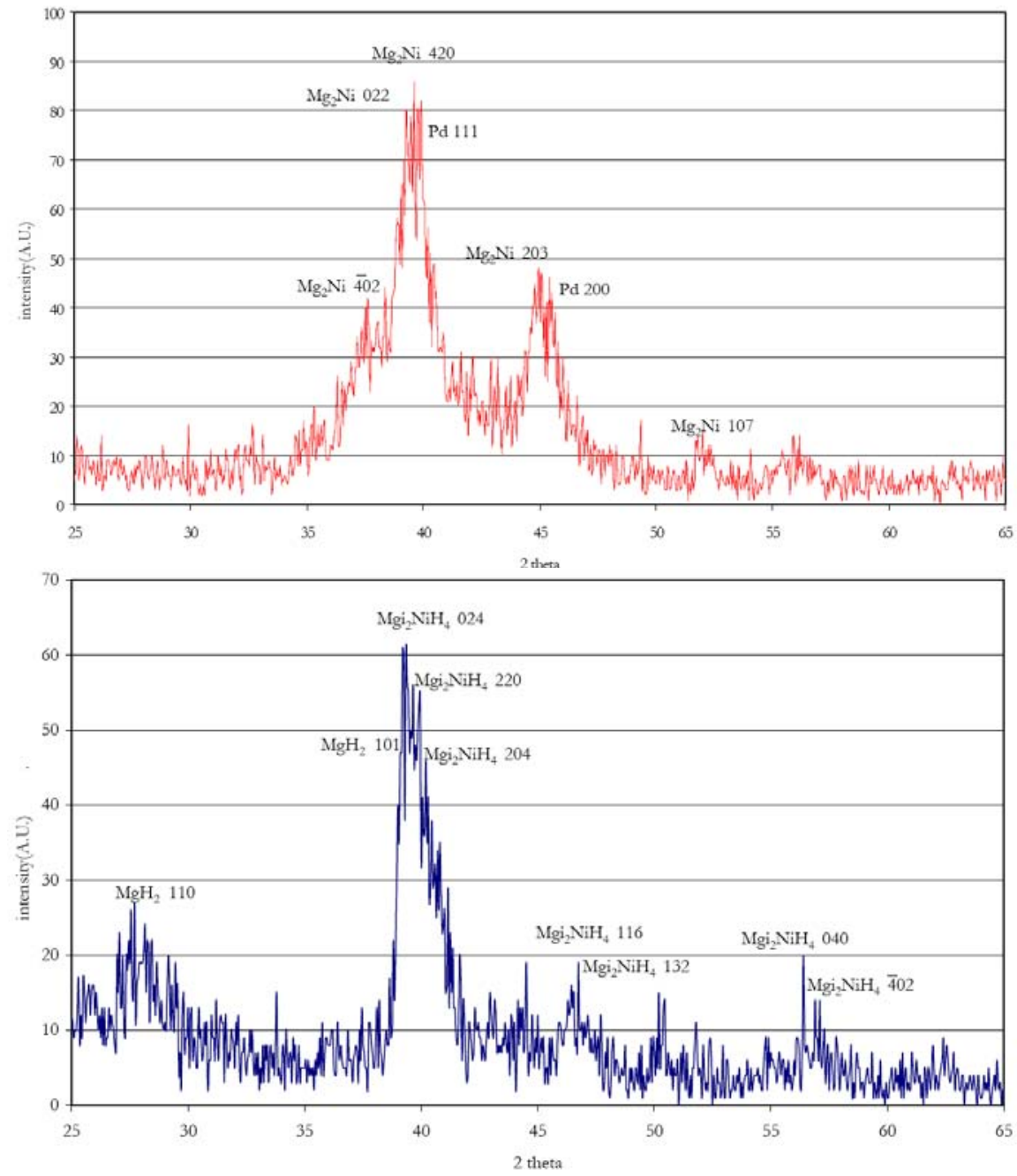

Figure 3. XRD patterns of a Mg-Ni alloy film before (a) and after (b) hydrogenation

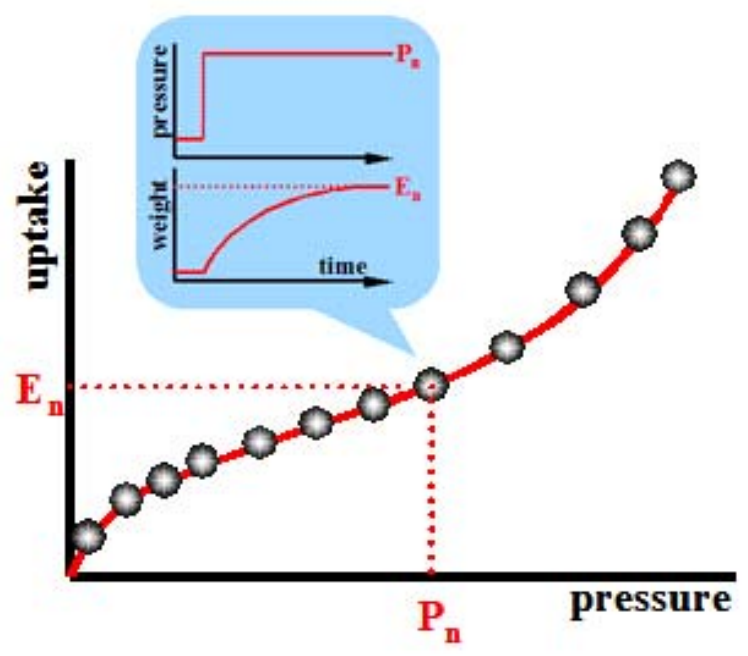

Figure 4. Schematic illustration of weight-based measurement of hydrogen uptake as a function of pressure (isotherm). 


\subsubsection{MgNi films with Pd capping}

To reach thick films for easier delamination and hydrogen storage characterization, relatively long experiments have to run. Films were deposited beginning with $3 \mathrm{~J} / \mathrm{cm}^{2}$ fluence at a vacuum of $2 \times 10^{-6}$. The film was collected on $\mathrm{Si}$ and $\mathrm{Cu}$ substrates. The Pd target was irradiated at $20 \mathrm{~Hz}$ for 10 minutes, followed by the Mg-Ni target at $20 \mathrm{~Hz}$ for 7 hours, followed by the Pd target once again at $20 \mathrm{~Hz}$ for 30 minutes.

The sample was loaded into the gravimetric machine for hydrogen storage measurements. Under vacuum, the sample was allowed to desorb for 24 hours. The sample was heated to 296C, and the weight was monitored for various pressures. Data points were collected by setting a fixed hydrogen pressure in the sorption chamber and monitoring the weight change of the sample as it absorbed or desorbed hydrogen. When a sample weight equilibrium was reached for a given hydrogen pressure, the pressure was then increased and the process repeated. The identical procedure was used for desorption, as well as data collection at other temperatures. Once measurements started, the sample was not exposed to air until all measurements were completed. Figure 5 shows the testing result of laser-deposited nanoparticle MgNi films capped with Pd. It can be seen from this graph that as the hydrogen pressure is increased, increased hydrogen storage capacity is achieved up to the measurement limit of 20 bar. Upon dehydrogenation, decreasing pressure does not immediately cause decreasing hydrogen storage. A large hysterisis is observable between the sorption and desorption curves. Once the hydrogen pressure is decreased to about 2 bar, a phase change is observable from the plateau pressure. This most likely corresponds to a change from the $\beta$ phase to the $\alpha$ phase. This phase transformation is not observed during the first cycle sorption. It can also be seen that the sample does not completely desorb the full hydrogen content that had been absorbed. At hydrogen pressure of 4 mbar, about $0.4 \mathrm{wt} . \%$ of hydrogen is still contained in the sample. The maximum storage capacity found on this first cycle was 1.9 wt.\% hydrogen.

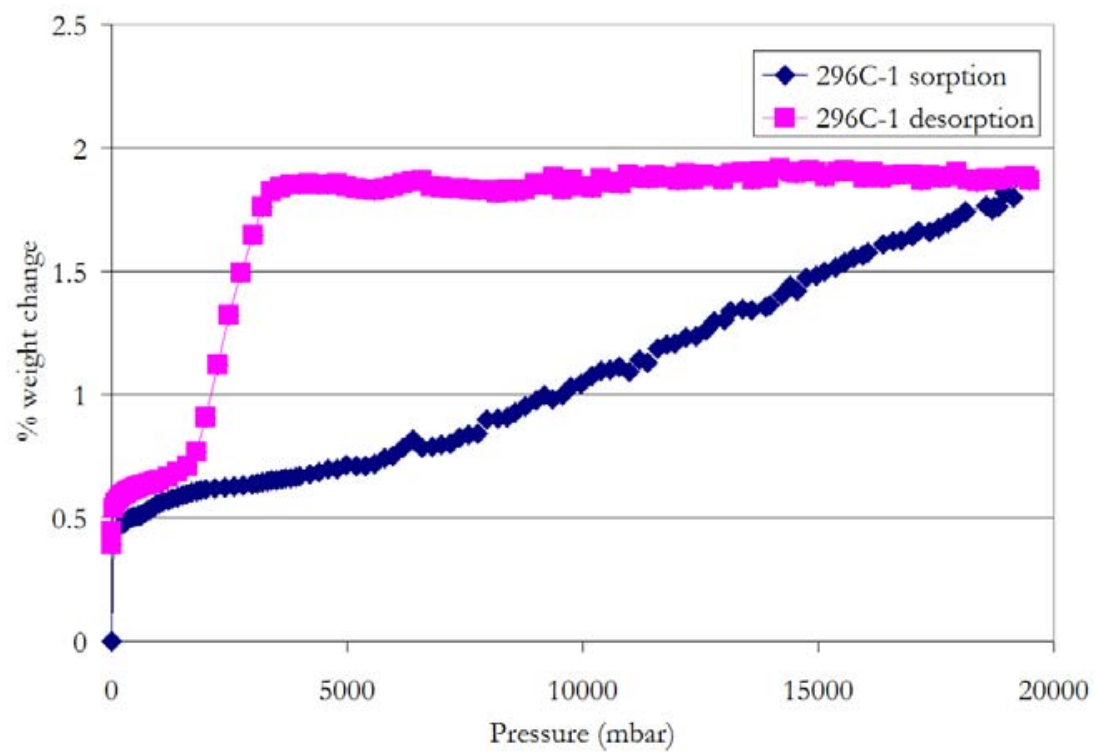

Figure 5. Sorption and desorption isotherm for the first cycle of the Mg-Ni sample (296C). 
Hydrogen sorption isotherms were found for three temperatures: $296 \mathrm{C}, 232 \mathrm{C}$, and $180 \mathrm{C}$. Figure 6 displays the results of the tests for the first cycle at each temperature. The maximum weight percentage stored is a strong function of both temperature and hydrogen pressure. Lower temperatures result in decreased sorption capacity. All temperatures exhibit a hysterisis between sorption and desorption, with the greatest hysterisis seen for the highest temperature case tested. The varying plateau pressures with temperature can be plotted in a van't Hoff plot, as shown in Figure 7. A fit of the three plateau pressures with a linear line allows calculation of the formation enthalpy and entropy, which were found to be $-76.5 \mathrm{~kJ} / \mathrm{mol} \mathrm{H}_{2}$ and $-138.7 \mathrm{~J} / \mathrm{K} \mathrm{mol} \mathrm{H}_{2}$, respectively.

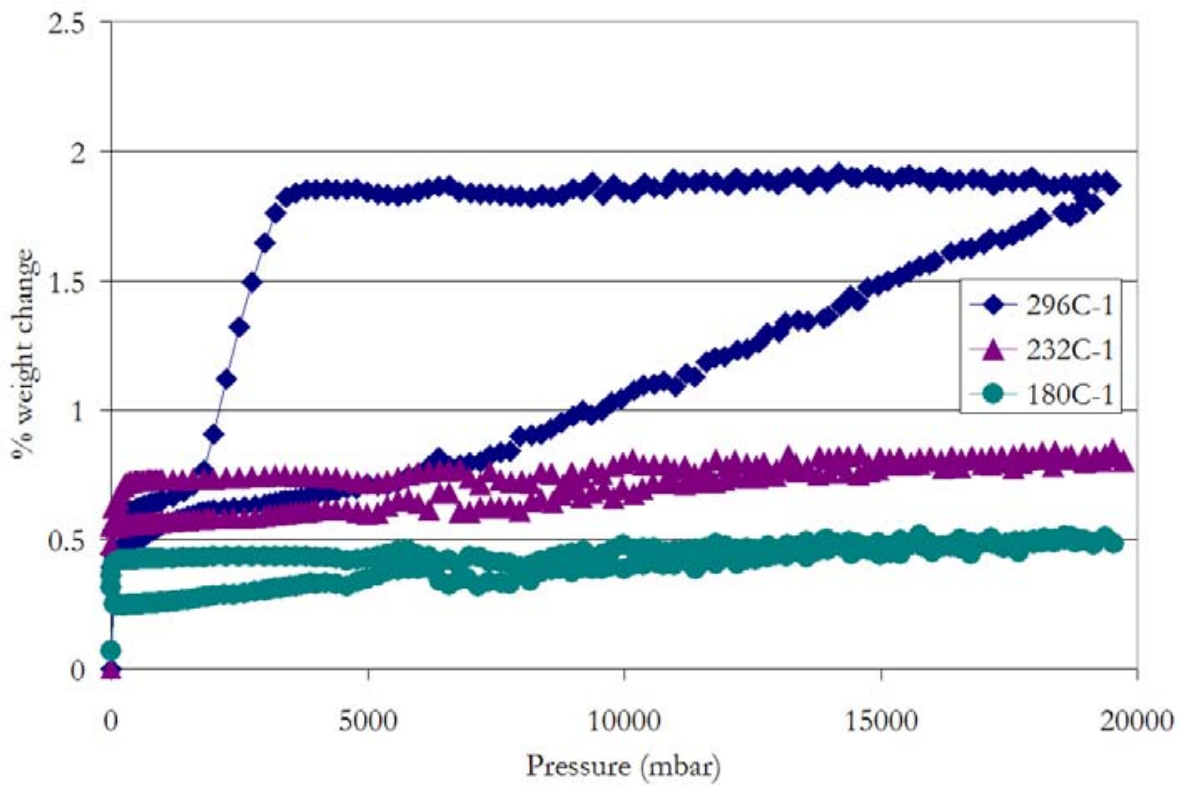

Figure 6. Hydrogen storage isotherms for $296 \mathrm{C}, 232 \mathrm{C}$, and $180 \mathrm{C}$ under otherwise identical loading conditions.

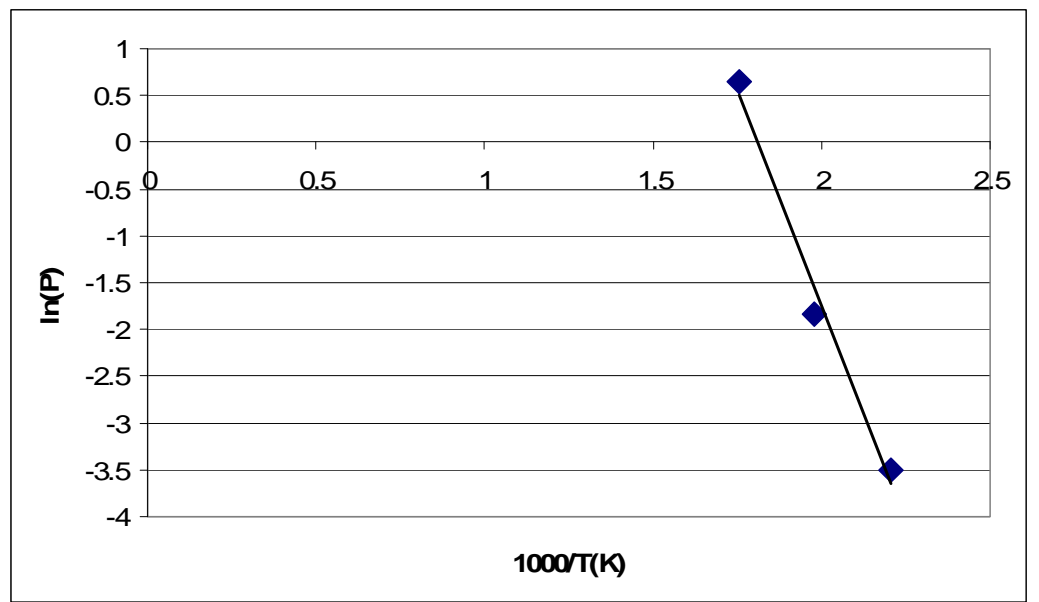

Figure 7. Van't Hoff plot of desorption plateau pressure as determined from Figure 6. 
The effects of cycling were also investigated for the deposited materials. Multiple full cycles were run at each temperature to investigate the change in hydrogen sorption capacity. Figure 7 clearly displayed the hysterisis between sorption and desorption, as well as the fact that the total amount of hydrogen absorbed was not released upon lowering the hydrogen pressure in the chamber. In this case, nearly $20 \%$ of the absorbed hydrogen at 20 bar remained in the sample with a pressure of only 4 mbar. Figure 8 shows that during the second cycle, approximately the same hydrogen storage capacity was reached. Desorption and a phase change occurred at a slightly higher equilibrium pressure, and a more observable phase change occurred during sorption.

Another important effect is implied from Figure 7, and that is the change from an amorphous or metallic glass like alloy to a more crystalline phase. The lack of a clear plateau pressure in the first sorption cycle is indicative of a range of interstitial environments for the hydrogen to occupy. The lack of order present in the amorphous phase resulting in no clear plateau pressure has been documented in the literature $[11,12]$.

The XRD scans taken before hydrogenation tests have very broad peaks as seen in Figure 7. This indicates a very small crystallite size according to the Scherrer equation. A clear desorption isotherm can be seen in the figure, indicating a decrease in the range of interstitial environments where the hydrogen is stored. These sorption tests were carried out at 296C, well below the individual melting temperature of the either magnesium or nickel, as well as the congruent. However, it should be noted that the amorphous melting temperature of a material can be much lower than the crystalline melting temperature, as in the case of Si where the amorphous melting temperature is almost $250 \mathrm{C}$ lower than the crystalline melting temperature [13]. Also, hydrogenation of this metal hydride is strongly exothermic. The exothermic reaction may create local hot spots where a raised temperature may exceed that needed for solid phase crystallization to occur, resulting in a change from amorphous to crystalline material. Nanocrystalline material

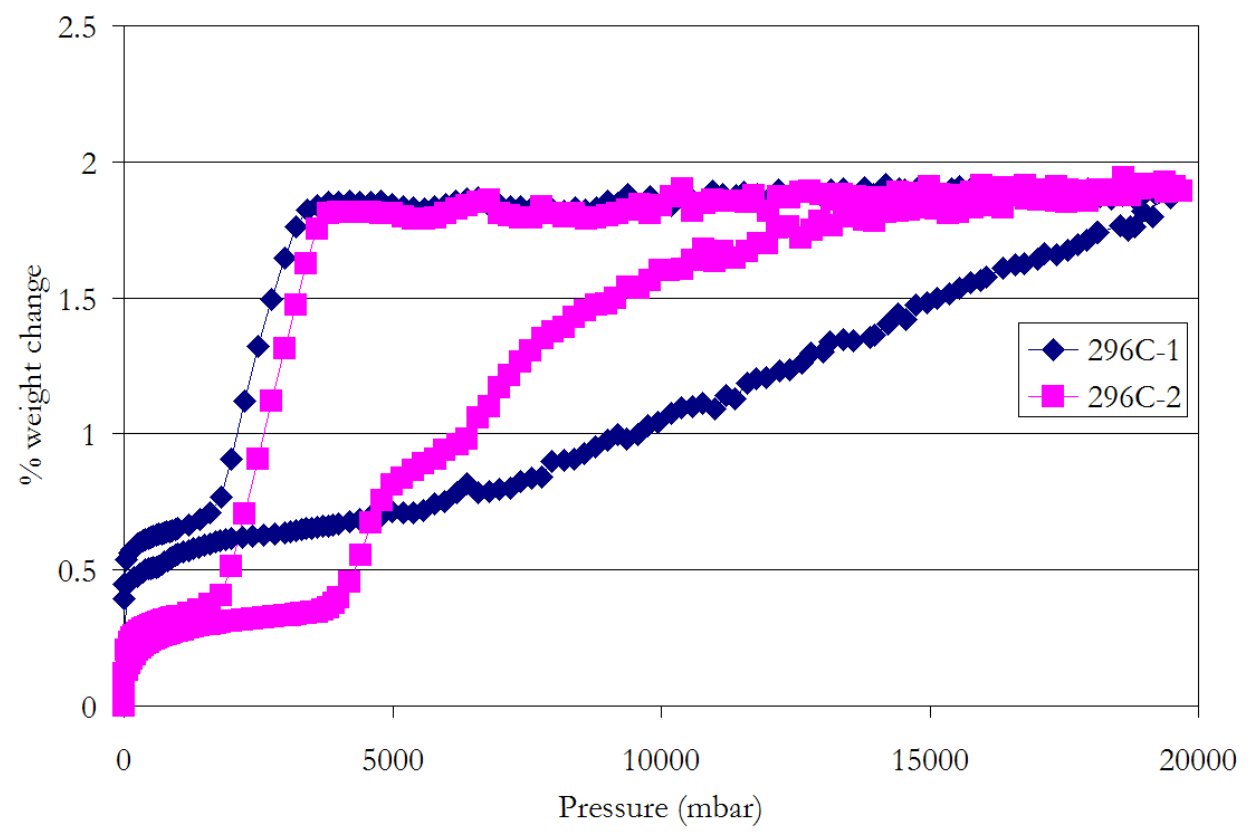

Figure 8. The first two cycles are shown at 296C. 
is expected to act with properties somewhere between the amorphous and crystalline phases of the material. Figure 8 displays a phase change pressure plateau during desorption, indicating an increased crystallinity occurred due to the sorption part of the first cycle. The second hydrogenation cycle shows the development of a pressure plateau, though it is not as sharp as that of a purely crystalline sample. It appears that a range of interstitial environments still exists for the hydrogen, though the sites are somewhat more uniform than during the first cycle. Again, the desorption isotherm shows a sharp transition and pressure plateau. The second cycle desorption isotherm pressure plateau is significantly longer than the first cycle, as indicated by the longer reversible weight percentage drop at near 2 bar. This increased pressure plateau length indicates an increase in crystallinity from the first desorption to the second desorption cycle. XRD scans of the sample after hydrogenation reveal that broad hydrogenation peaks remain, as seen in Figure 3. These results show that the initially deposited nanocrystalline Mg-Ni sample has been partially crystallized by hydrogen cycling at 296 C, but remains nanocrystalline in structure after at least three cycles at $296 \mathrm{C}$ (third cycle not shown) followed by three cycles at 232C (not shown but investigated before XRD characterization). The nanocrystalline nature of these films also helps to explain why decrepitation was not observed after hydrogen cycling. The ability of these films to avoid self pulverization due to the large volumetric change which occurs during hydrogenation is greatly improved over bulk crystalline samples $[14,15]$

In summary, free-standing alloyed films of magnesium and nickel have been successfully deposited by pulsed laser deposition. Films have been capped by a thin layer of palladium, and oxidation has been avoided. XRD has been used to characterize the structure of these films before and after hydrogenation. The hydrogen storage isotherms were found. Complete desorption did not occur at any temperature, but higher temperatures did desorb more hydrogen at higher hydrogen pressures than low temperatures. This residual hydrogen remaining in the $\mathrm{Mg}-\mathrm{Ni}$ alloys affected subsequent loading cycles, resulting in a smaller change between the reachable absorbed and desorbed cases. Cross sectional SEM of the films showed a porous nature of the nanoparticle films, correspondingly, the kinetics of transformation were very quick at low hydrogen pressures and raised temperatures. Calculation of the enthalpy and entropy of formation gave values comparable to those of magnesium.

\subsubsection{Mg films with Pd capping}

Thin films of Pd-Mg-Pd were initially studied nearly 20 years ago [5,16,17]. The motivation of the study came from the excellent kinetics, but poor storage capacity, that palladium exhibits; and the excellent storage capacity, but poor kinetics that magnesium possesses.

These published results have shown that the introduction of palladium as a capping layer can improve hydrogen dissociation and reduce the large activation barrier that magnesium inherently possesses. However, upon hydrogenation at low temperatures and pressures, a hydrided phase may kinetically block the stochiometry of $\mathrm{MgH}_{2}$. All previous investigations have studied films on a substrate. No kinetic information has been published, and hydrogen storage isotherms are not known for this system on or off a substrate. An ideal study would be one in which substrate affects can be eliminated by delamination prior to hydrogenation. 
A series of experiments were performed in which the hydrogen storage properties of PdMg-Pd films deposited by PLD and delaminated from the substrate were tested using the IGA Sorption. Samples were deposited under a vacuum of $2 \times 10^{-6}$ Torr at room temperature. The experimental design and procedure was essentially the same as that described in sections 2.2 . , with a bulk Mg target used instead of the Mg-Ni target. XRD results are shown in Figure 9. Both magnesium and palladium peaks can be clearly seen. A few peaks from the substrate exist as well. No peaks corresponding to $\mathrm{MgO}$ can be seen. After delamination, the films were placed in the quartz sample holder inside the sorption machine. Tests were run with the sample temperature at different temperatures; an increased sorption capacity at any pressure is realized with an increased temperature. Figure 10 displays sorption results for the first cycles at 290C, $137 \mathrm{C}$ and $23 \mathrm{C}$.

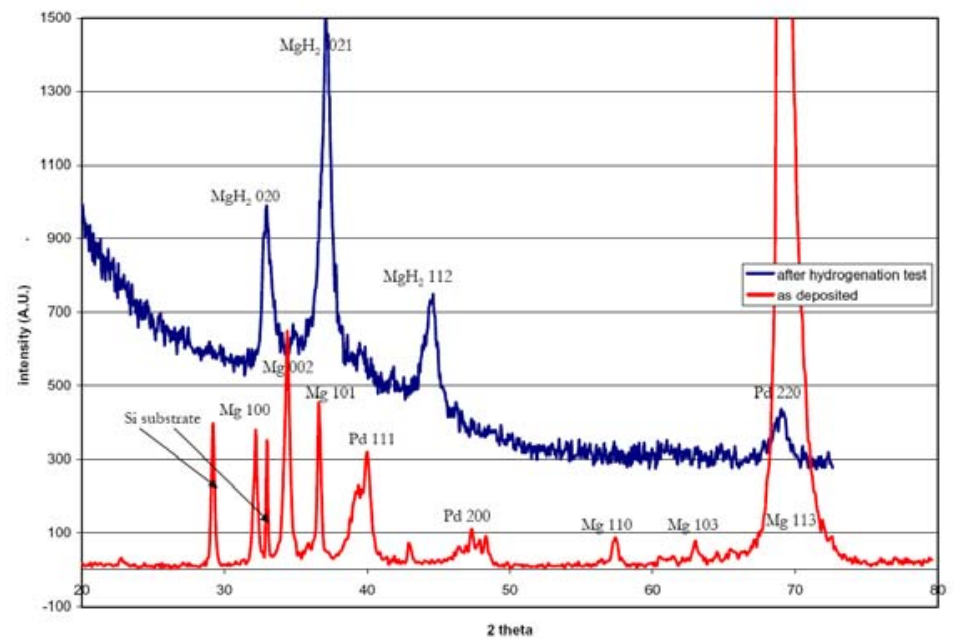

Figure 9. XRD results of Pd-Mg-Pd sample on silicon immediately after deposition and XRD result of the same sample after delamination and hydrogenation tests.

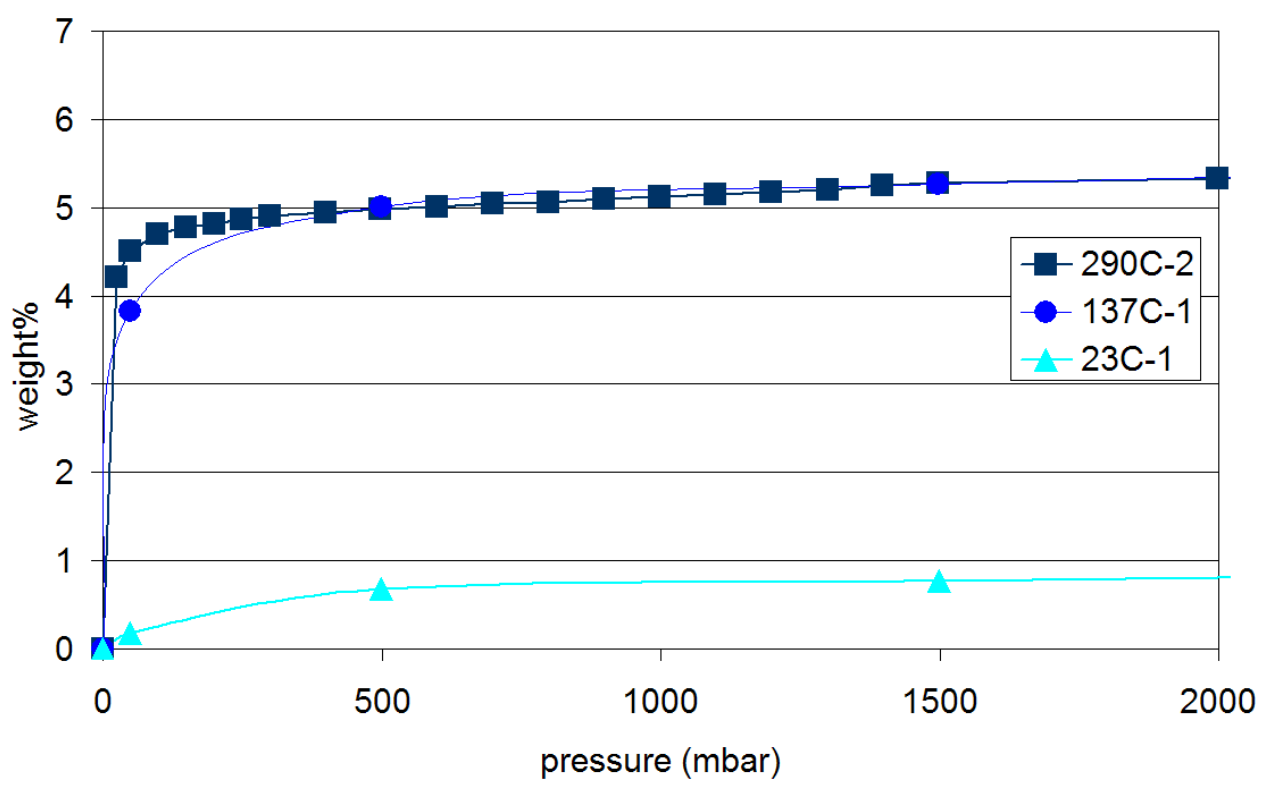

Figure 10. Hydrogen sorption of Pd-Mg-Pd system for the first cycle at 290, 137 and $23 \mathrm{C}$. 
The hysterisis that was observed for the Mg-Ni alloyed samples was also observed for films of Pd-Mg-Pd. Figure 11 shows weight percentage hysterisis observed between sorption and desorption at $23 \mathrm{C}$ for the first 3 cycles. This is not unique, and has been well documented in the literature for metal hydride systems. Figure 12 shows hydrogen storage capacity testings at 150C for three samples, a Pd-Mg-Pd nanoparticle film, a commercial $\mathrm{MgH}_{2}$, and a $\mathrm{Pd}$ metal. It can be seen that with $\mathrm{Pd}$ as the catalyst, at relatively low temperature (150C), hydrogen sorption is improved but desorption remains a problem.

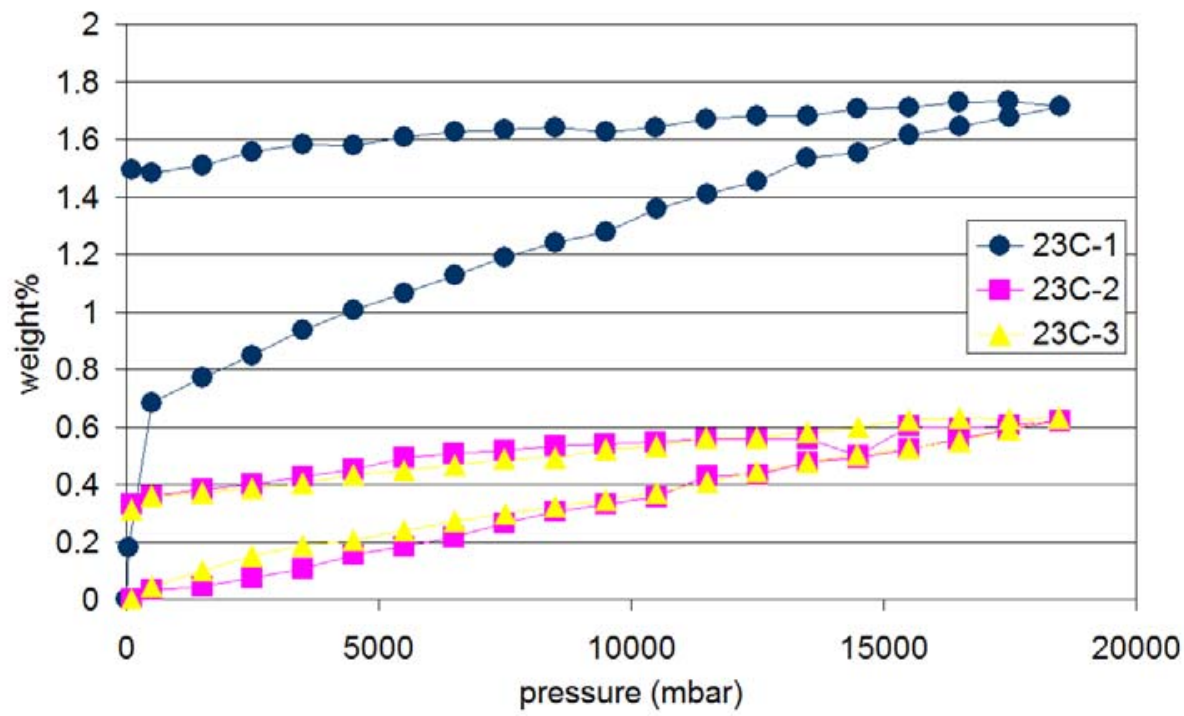

Figure 11. Weight percentage hysterisis observed between sorption and desorption at $23 \mathrm{C}$ for the first 3 cycles.

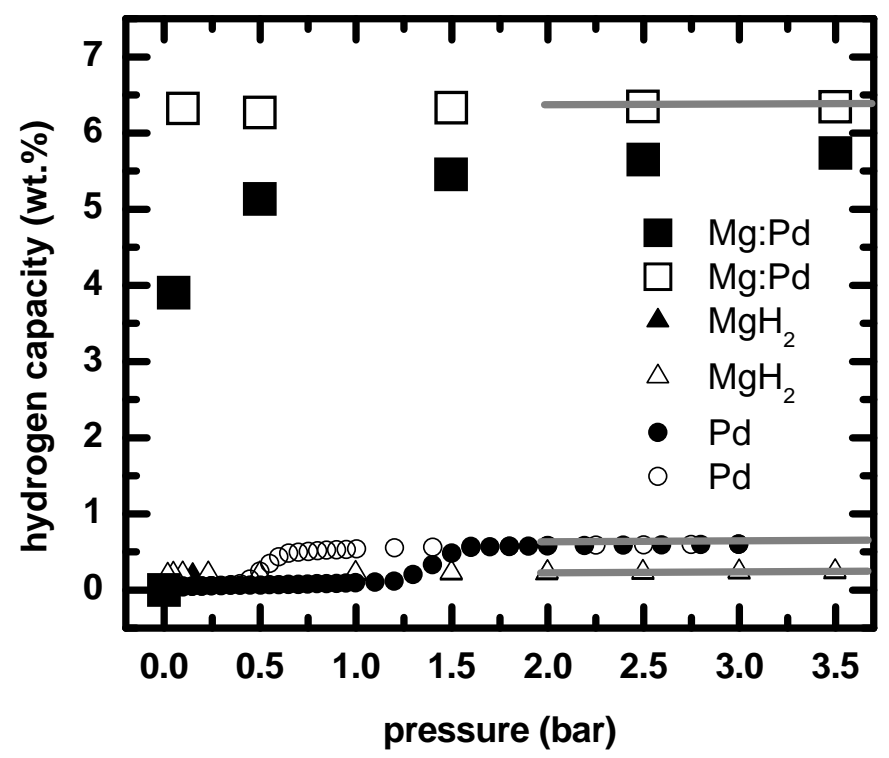

Figure 12. Hydrogen storage capacity testing at $150 \mathrm{C}$ for three samples: a Pd-Mg-Pd nanoparticle film, a commercial $\mathrm{MgH}_{2}$, and a Pd metal. 
Because pressure-isotherms were collected at various temperatures, a van't Hoff plot can be used to calculate the standard formation enthalpy and entropy for this case of PLD deposited Pd-Mg-Pd sample. Figure 13 displays the best fit line to the data points collected. The slope of the line can be used to calculate the enthalpy of formation and gives a value of $\Delta \mathrm{H}=-68 \mathrm{~kJ} / \mathrm{mol}$ $\mathrm{H}_{2}$. The y-intercept can be used to calculate the entropy of formation and gives a value of $\Delta \mathrm{S}=$ $135.5 \mathrm{~J} / \mathrm{K} \mathrm{mol} \mathrm{H}_{2}$. These values are close to the accepted published values.

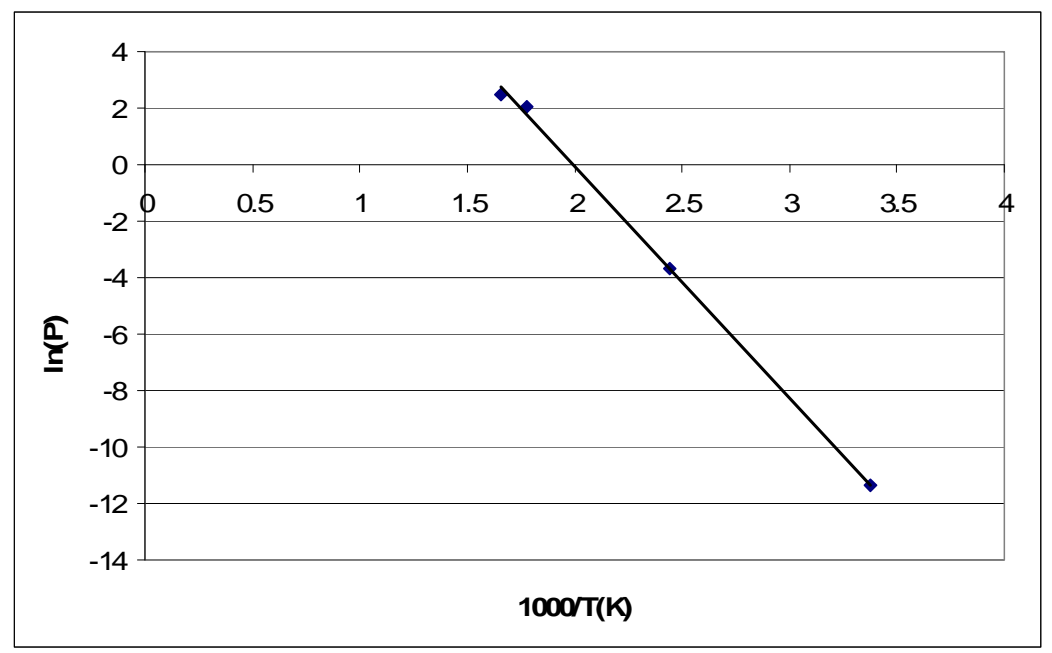

Figure 13. Van't Hoff plot showing the linearity of desorption pressure plateaus which can be used for calculating standard enthalpy and entropy of formation.

Lastly, XRD was performed on the delaminated, hydrogenated films. The results are shown in Figure 13 and have been vertically shifted for clarity; they are plotted along with the original XRD scan before hydrogenation with the sample still on the Si substrate. The overall diffraction intensity is decreased compared to the broad background due to the fact that the flakes do not take up as much area as the film on the silicon substrate. Many of the flakes were overlapping and space existed between flakes. These facts lead to the overall decreasing intensity trend with increasing angle. No peaks corresponding to magnesium are observed. This agrees with both the results of Krozer and Ryden in which the metal hydride forms at the palladium magnesium interface, and the results of Higuchi, in which XRD scans of partially hydrogenated palladium-magneisum films no longer displayed $\mathrm{Mg}$ peaks, and only displayed $\mathrm{MgH}_{2}$ peaks despite the fact that there was excess magnesium.

In summary, successful deposition and hydrogen storage testing of Pd-Mg-Pd films free from substrate effects has been accomplished. Hydrogen sorption and desorption trends with temperature, pressure, and cycle number are identical to that previously observed for the $\mathrm{Mg}-\mathrm{Ni}$ alloys, and agrees well with published results in the literature for both ball milled materials and films deposited on a substrate. These experiments show the first successful weight change test of the Pd-Mg-Pd film free from the effects of a substrate and the results compliment the previous experimental results in which the hydrogen storage in the Pd-Mg-Pd system on a substrate was investigated. 


\section{Combinatorial Screening}

\subsection{Synthesis}

Using a high throughput combinatorial material synthesis approach, it is possible to analyze a wide variety of complex metal hydride systems. By combining three materials, we can study the optimal ratio of metals such as $\mathrm{Mg}$ and $\mathrm{Ni}$, while using a third element such as $\mathrm{Ti}$ to catalyze the reaction [18]. Magnesium-Aluminum-Nickel samples were studied due to the favorable possibilities of both $\mathrm{Mg}-\mathrm{Al}$ and $\mathrm{Mg}-\mathrm{Ni}$ systems. $\mathrm{Mg}-\mathrm{Ni}$ in particular has been studied extensively, but no optimal composition has yet been found. The sample was created with two layers of each material deposited on a glass substrate. Each layer of material was designed to be $20 \mathrm{~nm}$ at one corner and taper down to $0 \mathrm{~nm}$ at the opposite edge, with one corner designated for each material. The sample was then capped with a $15 \mathrm{~nm}$ palladium layer to act as a catalyst and prevent oxidation. Fig. 14 shows the RBS measurements of the individual layers of sample.

The sample was tested at $150{ }^{\circ} \mathrm{C}$ in $300 \mathrm{psi} \mathrm{H}_{2}$. The sample showed a significant change after hydrogenation in some area of the sample, as shown in Figure 15. From the point of view of likely faster kinetics for hydrogen storage, elemental ratios that fall into that largest area of change are most promising. We are working on more detailed characterization of these samples.

\subsection{Optical Reflectance Characterization}

When a metal stores hydrogen through chemisorption, a fundamental change in material properties occur. For instance, interstitial sites filled with hydrogen will bond to the host metal lattice either covalently or ionically. The result is a change in crystal structure, and electronic properties. For example, when $\mathrm{Mg}$ changes to $\mathrm{MgH}_{2}$, a highly conducting metal changes to an insulator. $\mathrm{MgH}_{2}$ possesses an indirect band gap with an absorption edge at about $5.16 \mathrm{eV}$. Thus only light with energy above $5.16 \mathrm{eV}$ will be directly absorbed. Equivalently, only light with a wavelength below $240 \mathrm{~nm}$ has sufficient energy to overcome the band gap and be directly
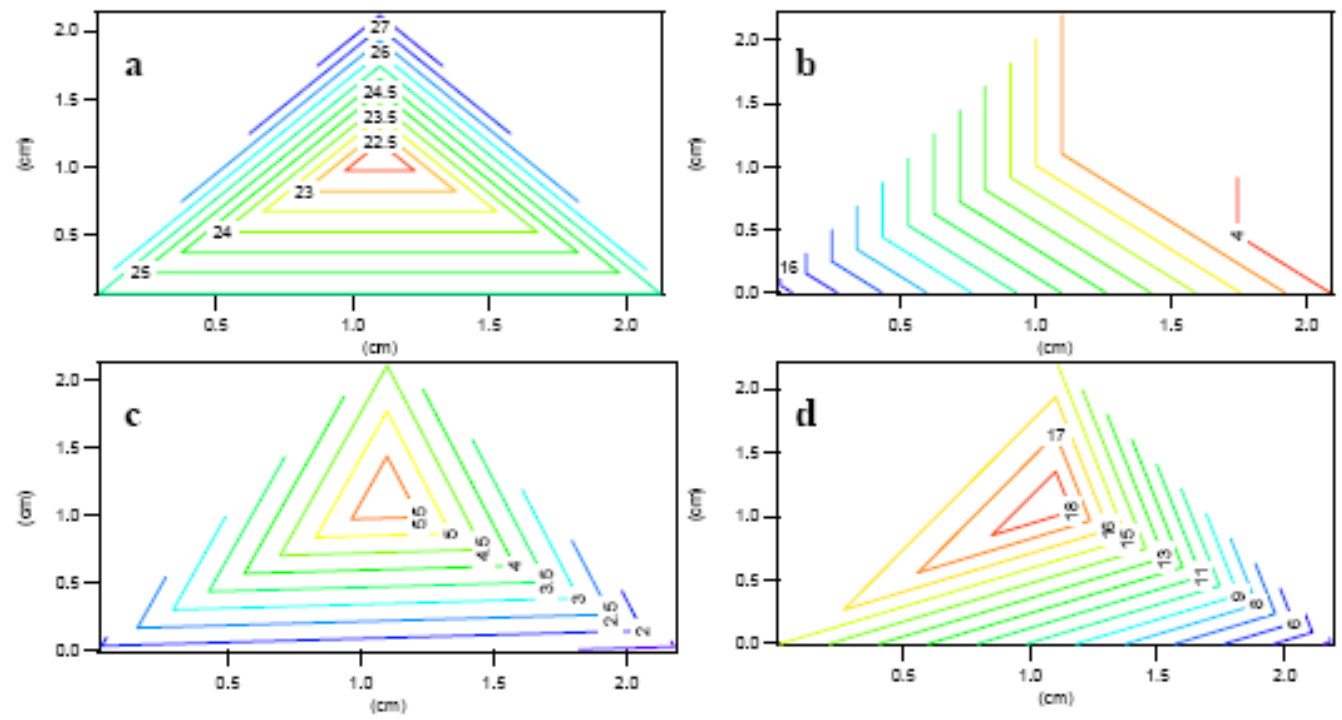

Figure 14. Thickness (nm) maps for (a) $\mathrm{Pd}$, (b) $\mathrm{Al}$, (c) Ni, and (d) $\mathrm{Mg}$, in a continuous combinatorial sample. 

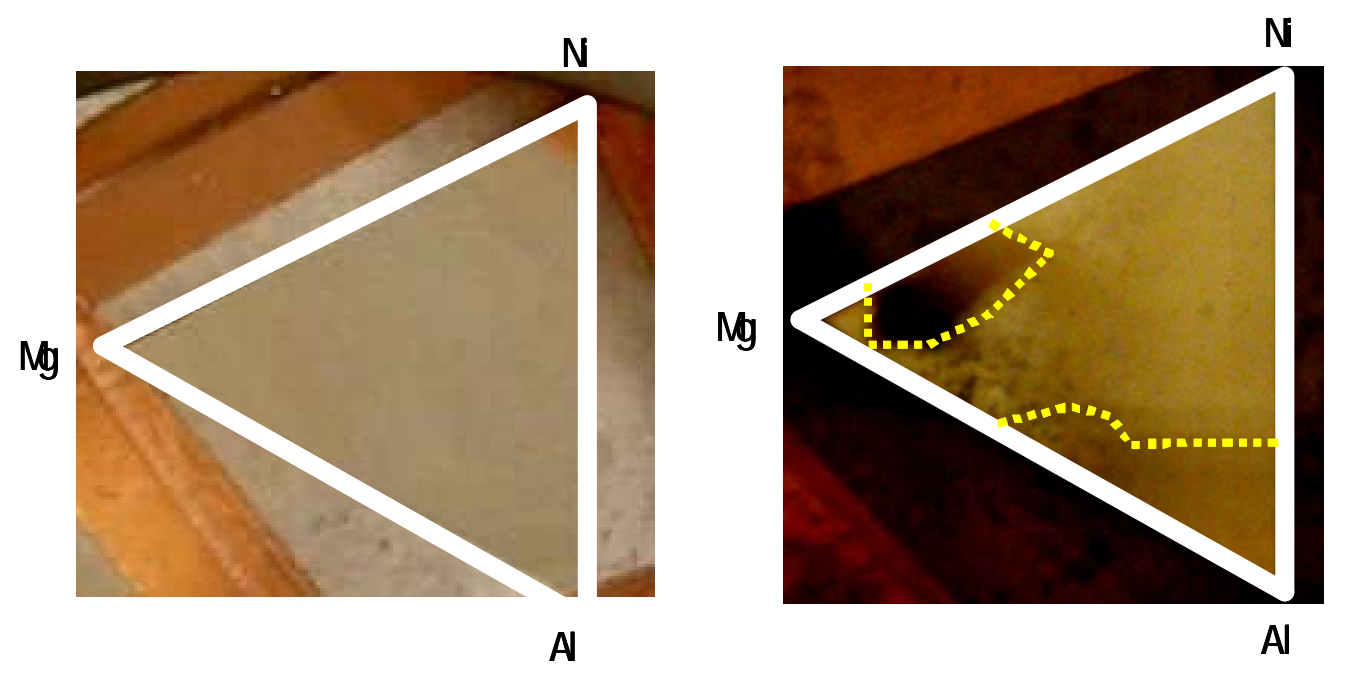

Figure 15. (a) A photo of Mg-Ni-Al sample before hydrogenation. (b) A photo of the same sample after hydrogenation at $150^{\circ} \mathrm{C}$.

absorbed [19,20]. Thus thin films of $\mathrm{MgH}_{2}$ appear transparent in the visible light regime. Similarly, a film of $\mathrm{Mg}_{2} \mathrm{Ni}$ can be changed from highly reflecting to almost completely transparent by hydrogenation. A band gap of approximately $1.9 \mathrm{eV}$ forms; or equivalently, light must have a wavelength shorter than $650 \mathrm{~nm}$ to be directly absorbed by the film. This band gap causes the hydride to appear colored, as it exists in the visible range.

Reflectance measurements were taken using an Nd:YAG laser at a wavelength of 1046 nm. Near infrared light was used because metal hydride systems often show the largest change in reflectance and transmittance in this range due to the opening of a band gap [21]. The chamber was placed on an $\mathrm{X}-\mathrm{Y}$ stage to measure the reflectance of various points on the sample without changing the optical setup. As illustrated in Figure 16, points were measured $5 \mathrm{~mm}$ apart across the entire sample before and after exposure to hydrogen at 300 psi.

Figure 17 shows the percent decrease in reflectance in the $\mathrm{Mg}-\mathrm{Ni}-\mathrm{Al}$ sample after exposure to 300 psi hydrogen for 1 hour. The sample shows a relatively uniform decrease in

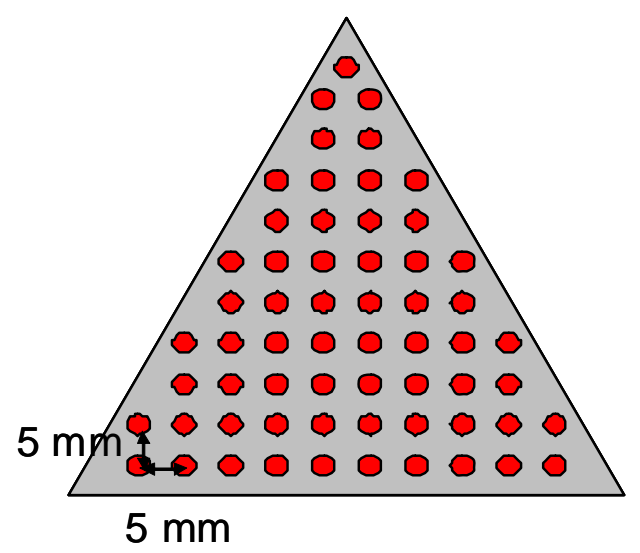

Figure 16. Schematic of measurement points on a combinatorial material sample. 


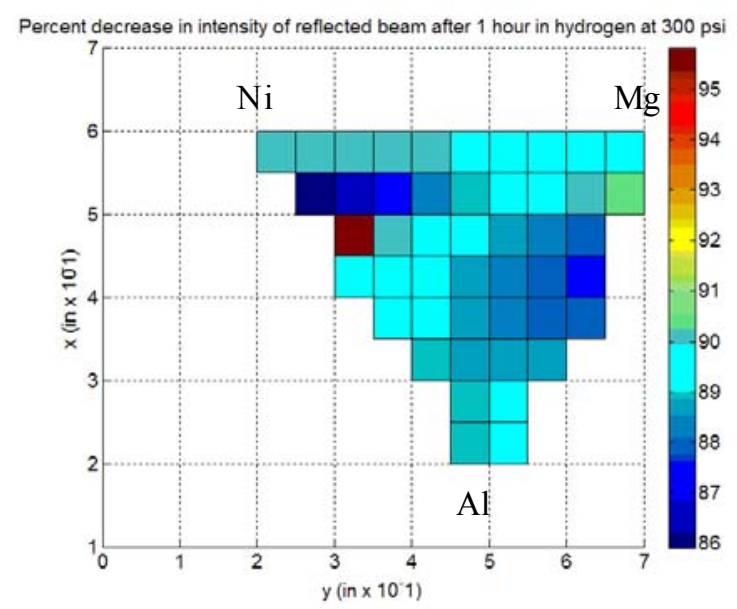

Figure 17. Decrease in reflectance of an $\mathrm{Mg}-\mathrm{Ni}-\mathrm{Al}$ sample exposed to $300 \mathrm{psi} \mathrm{H} 2$ for 1 hour.

reflectance, ranging from roughly 87 to $91 \%$ across the majority of the measured points. This is consistent with the results reported by Westerwaal et al. [22], who reported a maximum dip in reflectance of $83 \%$ during hydrogen absorption.

Calcium-Boron-Titanium samples were tested due to the favorable properties of calcium diborohydride, $\mathrm{Ca}\left(\mathrm{BH}_{4}\right)_{2}$, which has a theoretical weight percentage of hydrogen of $11.5 \%$. Titanium was included due to its potential to act as a catalyst for hydrogen uptake [18]. Heating the sample to $150{ }^{\circ} \mathrm{C}$ did not significantly change the reflectance of the sample (Fig. 18a). Adding hydrogen at 300 psi to the sample at $150{ }^{\circ} \mathrm{C}$ caused a drop in reflectance across the sample. The center of the sample has a smaller change in reflectance (Fig. 18b), implying that there was less of a reaction. It is possible that the sample is mainly titanium hydride near the bottom area of the figure, and calcium borohydride near the top, with a middle area where no favorable hydride is formed.

(a)

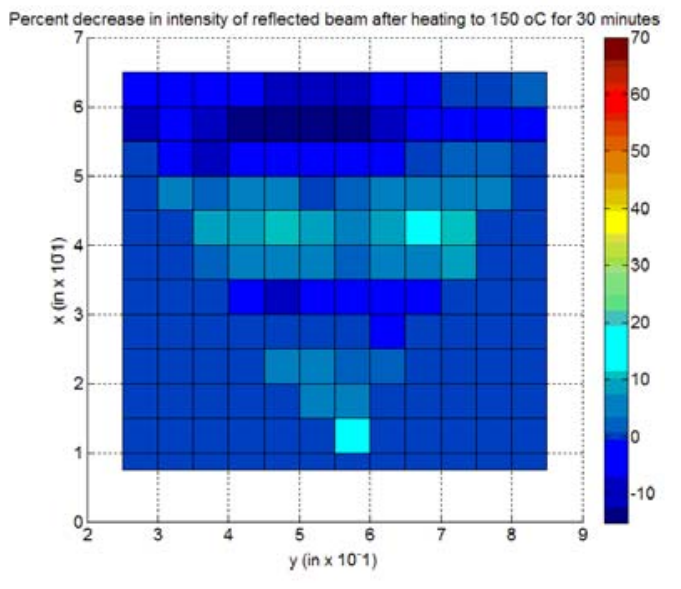

(b)

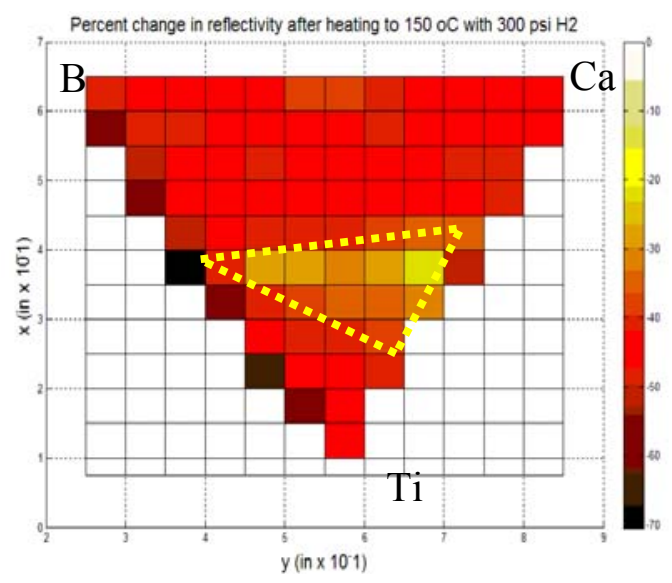

Figure 18. (a) Percentage change in reflectance after heating to $150{ }^{\circ} \mathrm{C}$ in Argon for 30 min. (b) Percentage decrease in reflectance after heating to $150{ }^{\circ} \mathrm{C}$ in $300 \mathrm{psi}_{2}$ for 1 hour. The area marked by yellow dotted lines has smaller change of reflectance. 
Figure 19 shows an in situ reflectance measure on a magnesium-nickel-boron sample, which was heated to $100{ }^{\circ} \mathrm{C}$ and exposed to $300 \mathrm{psi}_{2}$. The figure shows decrease in reflectance over 100 minutes at the measurement spot. There is a 20 minutes delay in this measurement due to the current configuration of the setup. A modification of the testing cell has been designed and is currently under construction, for which the entire history of reflectance change can be captured.

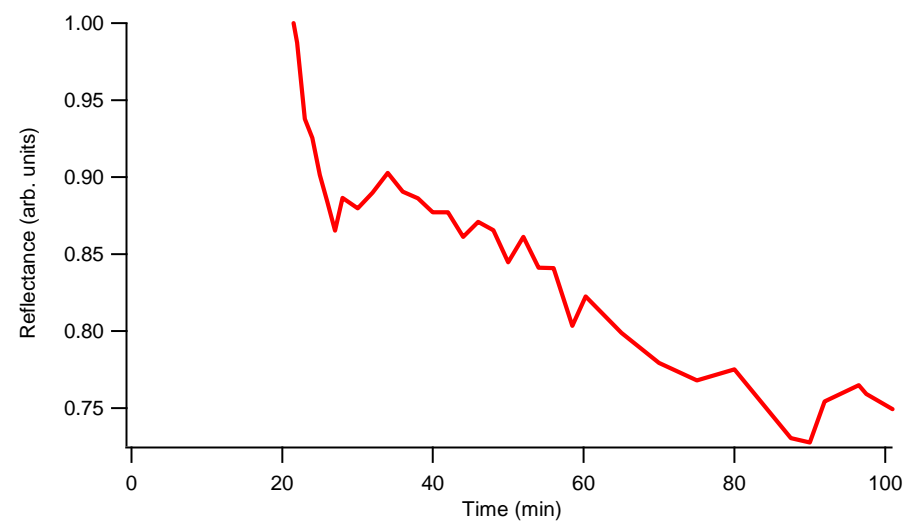

Figure 19. Magnesium-Nickel-Boron sample heated to $100{ }^{\circ} \mathrm{C}$ and held in $300 \mathrm{psi}_{2}$ for 1 hour. Measurements were taken at a spot near Mg corner of the sample.

\subsection{Pump-and-Probe Characterization}

We developed an optical pump-and-probe experimental system to characterize thermal properties of metal hydride films. In a pump-and-probe experiment, a femtosecond laser beam is split into two beams. One (pump-beam) is directed onto the sample, creating a transient temperature rise on the surface. The second beam (probe-beam) is time delayed with respect to the first one and measures the reflectance change due to the pump-beam heating. From the temporal decay signals, thermal properties of the underlying layers can be extracted. Figure 20 shows an example of the pump-probe measurements on four spots of a ternary combinatorial library, schematically illustrated in the insert of the figure.

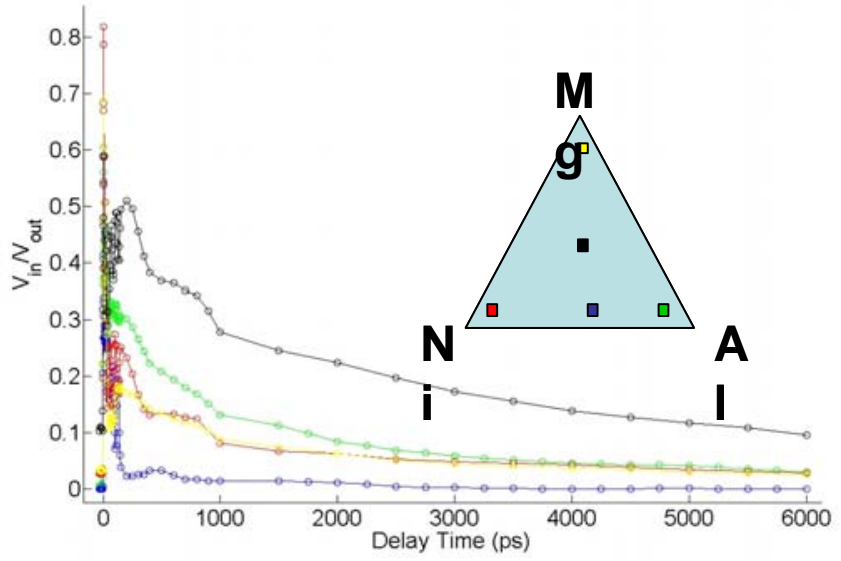

Figure 20. Time-resolved pump-probe measurements at four spots of a ternary combinatorial library, schematically illustrated in the insert of the figure (color coded in line with the data curves). 


\section{Catalyzed Metal Hydride in Porous Materials}

Porous materials, with good absorption/desorption reversibility have been extensively studied in the past decades for hydrogen storage [23]. Examples are metal-organic framework, carbon nanotubes, and other porous materials [24]. These material systems, however, have very low storage temperatures. Another type of storage system is metal hydrides [25-27], which are safe and volume-efficient storage systems. Yet higher hydrogen release temperatures resulting from their unfavorable thermodynamic and kinetic property are required. Also, when recycled, the fine particles of hydrides agglomerate to form larger solids, which further reduce kinetics. Hydrides coated with catalysts should be supported in a matrix that provides a stable and recyclable structure. A storage system with hydrogen-containing molecules embedded in a matrix has been studied by Autrey and coworkers [28]. They coated ammonia borane within the mesoporous silica SBA-15. Their study shows that hydrogen materials embedded in porous materials or nanoscaffold could bring in both chemisorption and physisorption effects, and could suppress agglomeration of solid hydrides. The nanoscaffold can also contribute to the thermodynamics and kinetics by limiting particle size and thus diffusion distance.

\subsection{Experimental}

\subsubsection{Hydride Sol-Gel synthesis}

In a typical ball mill experiment, a mixture of $7 \mathrm{~g} \mathrm{MgH} 2$ (Alfa Aesar) with $2 \mathrm{~mol} \% \mathrm{Ni}$ and together with stainless steel balls, with a weight ratio of the sample to ball is $1: 10$, were put into a steel vial. All the samples were handled in a glove box filled with argon to minimize the oxidation on the samples. The mixture was then milled using a ball mill apparatus (Spex SamplePrep 8000 Series Mixer/Mill) for 2 hours. After that, in the synthesis of MgH2-aerogels [29], first a portion of tetramethylorthosilicate (TMOS) $(88.5 \mathrm{ml}$, Sigma), distilled water(43.2ml) and methanol(145.8ml, Alfa Aesar) were mixed into a beaker, which was then stirred for $2 \mathrm{~h}$ for hydrolysis. Then, $4 \mathrm{~g}$ of milled powder of $\mathrm{MgH} 2$ was added into $6 \mathrm{~g}$ of the sol, and was kept stirred for a few seconds. $0.5 \mathrm{ml} 2 \mathrm{M} \mathrm{NH3}$ (in methanol) was involved to introduce gelation. The wet $\mathrm{MgH} 2 / \mathrm{Ni}$ gels were put into anhydrous ethanol immediately after gelation. The gels were washed using ethanol several times to remove all the residue water, and were aged for a week. The wet $\mathrm{MgH} 2 / \mathrm{Ni}$ gels were then dried with supercritical CO2. Dried gels were ready for characterizations.

\subsubsection{Sample Characterizations}

$\mathrm{MgH}_{2} / \mathrm{Ni}$-aerogels were crushed into powder for further tests. The morphology of the composite particle was examined by Scanning Electron Microscopy (SEM) (JEOL 6400F), and the element distribution in the aerogel was detected by the energy dispersive X-ray spectroscopy (EDS) equipment (Oxford Isis). The structural properties of the samples were examined by X-ray diffraction measurement (Rigaku D-max/B) using $\mathrm{Cu} \mathrm{K \alpha}$ radiation. Desorption and thermal behavior of milled hydride powder and hydride embedded aerogels were studied by differential scanning calorimetry (DSC) and thermo gravimetric analysis (TGA, TA instruments). All the samples were tested using DSC with a heating rate of $5^{\circ} \mathrm{C} / \mathrm{min}$ under argon protection at ambient pressure. All the samples were also tested using TGA with a heating rate of $15^{\circ} \mathrm{C} / \mathrm{min}$ under argon protection at ambient pressure. 


\subsection{Results for composite hydride materials}

Figure 21 is the SEM image that demonstrates morphology of ball milled $\mathrm{MgH}_{2} / \mathrm{Ni}$ powder and $\mathrm{MgH}_{2} / \mathrm{Ni}$-aerogel, respectively. It can be seen that there is no apparent change in the particle sizes for $\mathrm{MgH}_{2}$. In the $\mathrm{MgH}_{2}$ /aerogel sample, the particles were surrounded by some shells, the silica aerogel structures, implying that $\mathrm{MgH}_{2}$ was embedded in the aerogel matrix.
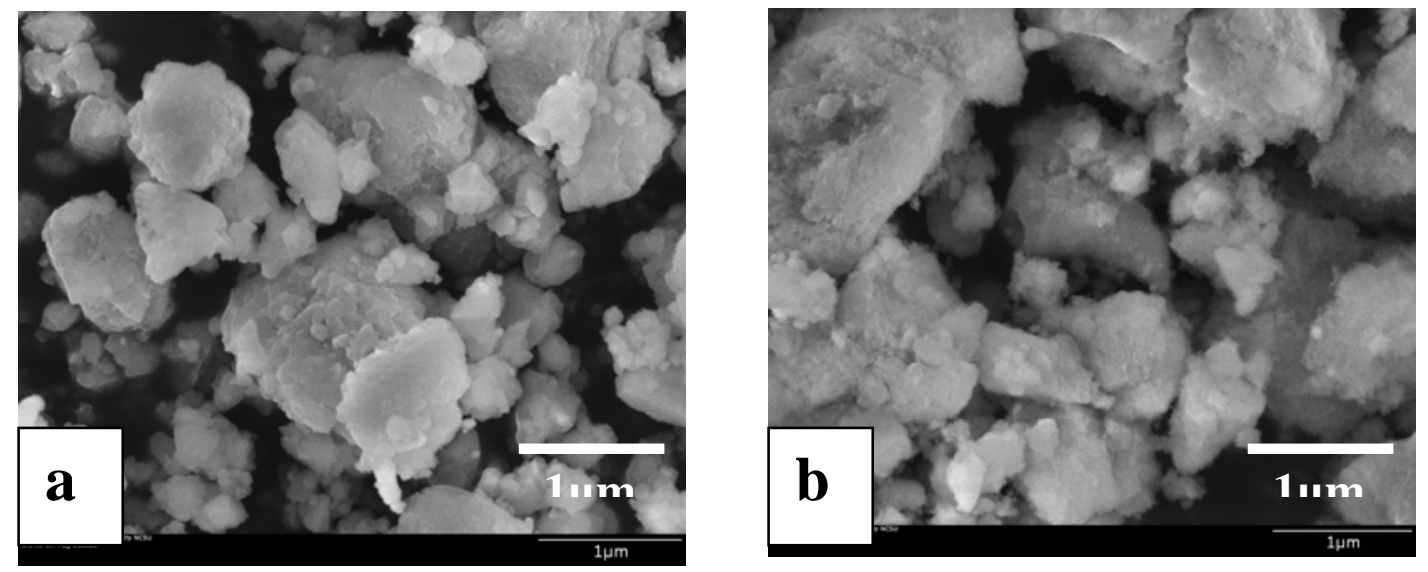

Figure 21. SEM micrograph of the morphology of ball milled $\mathrm{MgH}_{2} / \mathrm{Ni}$ powder (a), and $\mathrm{MgH}_{2} / \mathrm{Ni}$-aerogel (b)

Figure 22 is the X-ray map for the elemental profiles in $\mathrm{MgH}_{2} / \mathrm{Ni}$-aerogel. Channel 1 is the $\mathrm{MgH}_{2} / \mathrm{Ni}$-aerogel's area that was spotted. The blue spots reflect the distribution information of $\mathrm{Mg}$ element, and the red spots reflect the distribution information of silicon. Where there is a relatively large amount of magnesium, there is a relatively small amount of silicon. This indicates that magnesium hydride was well embedded within the silica structure. The distribution of nickel particles is reflected by yellow spots. But due to the very small amount of nickel that was added during ball milling, the collected information can barely identify the distribution of $\mathrm{Ni}$ by EDS.

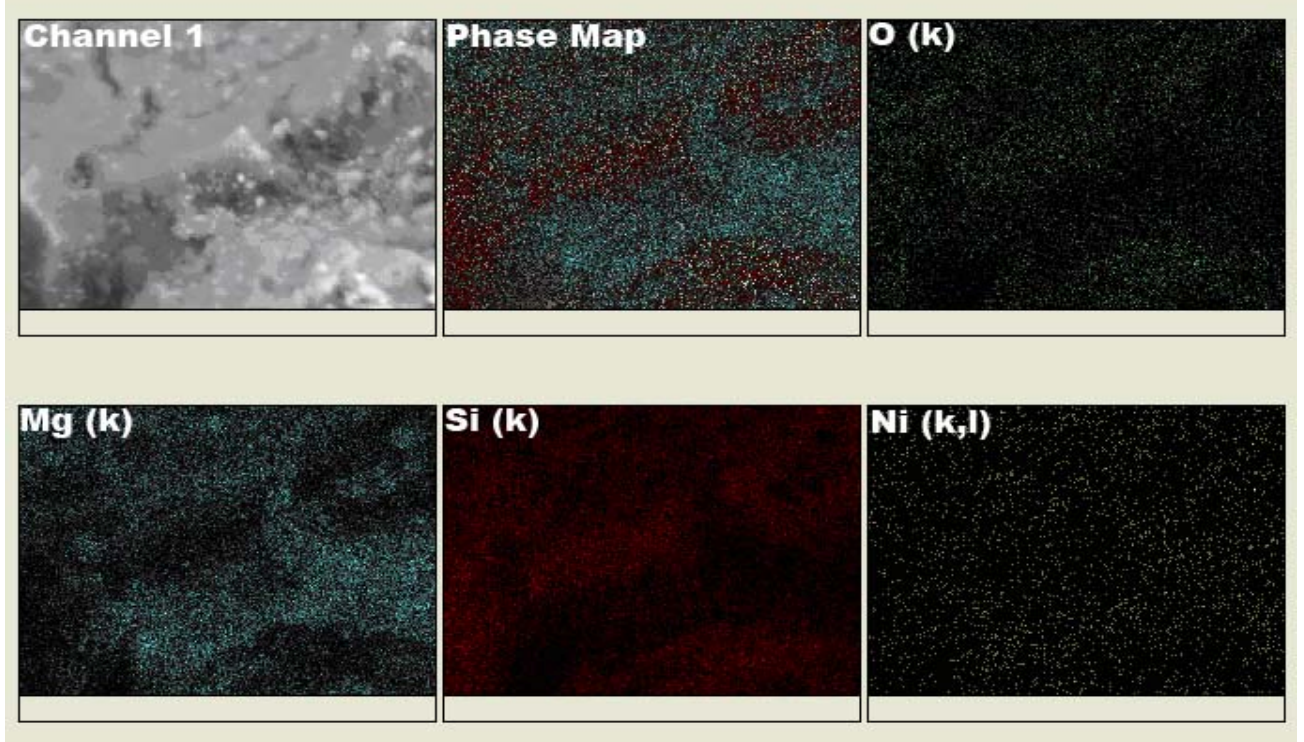

Figure 22. X-Ray map for the elements distribution of $\mathrm{MgH}_{2} / \mathrm{Ni}$-aerogel 
Figure 23 shows the $\mathrm{X}$-ray diffraction profiles for the milled powder of $\mathrm{MgH}_{2}$ with $2 \mathrm{~mol} \% \mathrm{Ni}$ and the $\mathrm{MgH}_{2} / \mathrm{Ni}$-aerogel. It can be seen that peaks the for $\beta-\mathrm{MgH}_{2}, \gamma-\mathrm{MgH}_{2}$ and Ni in the milled powder can be easily specified, while neither $\mathrm{Mg}_{2} \mathrm{NiH}_{4}$ nor $\mathrm{Mg}_{2} \mathrm{Ni}$ were formed during the milling, which means that no alloys were formed during the short milling process. A tiny amount of $\mathrm{MgO}$ was observed, which we attribute to the oxygen residue associated with the raw $\mathrm{MgH}_{2}$ and in the stainless steel vial during ball milling. Comparing those two profiles, one can tell that the main profile for the $\mathrm{MgH}_{2} / \mathrm{Ni}$-aerogel is exactly the same as that of the purely milled $\mathrm{MgH}_{2} / \mathrm{Ni}$ powder. It also demonstrates that no apparent oxidation of $\mathrm{MgH}_{2}$ occurred during the hydride embedded sol-gel synthesis. It is worthwhile to point out that all the peaks are quite broad, implying that $\mathrm{MgH}_{2}$ particles' grain size in both ball milled $\mathrm{MgH}_{2} / \mathrm{Ni}$ power and $\mathrm{MgH}_{2} / \mathrm{Ni}$-aerogel are distributed in a very small and similar size range.

The pore size distribution analysis for the $\mathrm{MgH}_{2} / \mathrm{Ni}$-aerogel composite was performed by the BET. The measurement shows a bi-modal distribution with a surface area of $155 \mathrm{~m}^{2} / \mathrm{g}$, which is relatively small compared to that of pure aerogel synthesized under the same condition. The relatively small surface area for the composite is attributed to the large mount of magnesium hydride powder embedded inside the aerogel structure that has a size of micrometers.

Figure 24 shows the DSC profiles for milled hydride powder and its corresponding aerogel composite, and $\mathrm{TiO}_{2}$-aerogel composite which has the same amount of $\mathrm{TiO}_{2}$ powder added during sol-gel synthesis as the amount of hydride powder added for $\mathrm{MgH}_{2}$-aerogel composite. It can be seen that the milled hydride powder has two hydrogen releasing peaks: One is peaked at $289^{\circ} \mathrm{C}$, and the other is at $363^{\circ} \mathrm{C}$, which is consistent with previous researchers' findings[26]. We attribute the two release temperature ranges to the bimodal distribution of the $\mathrm{MgH}_{2}$ particles

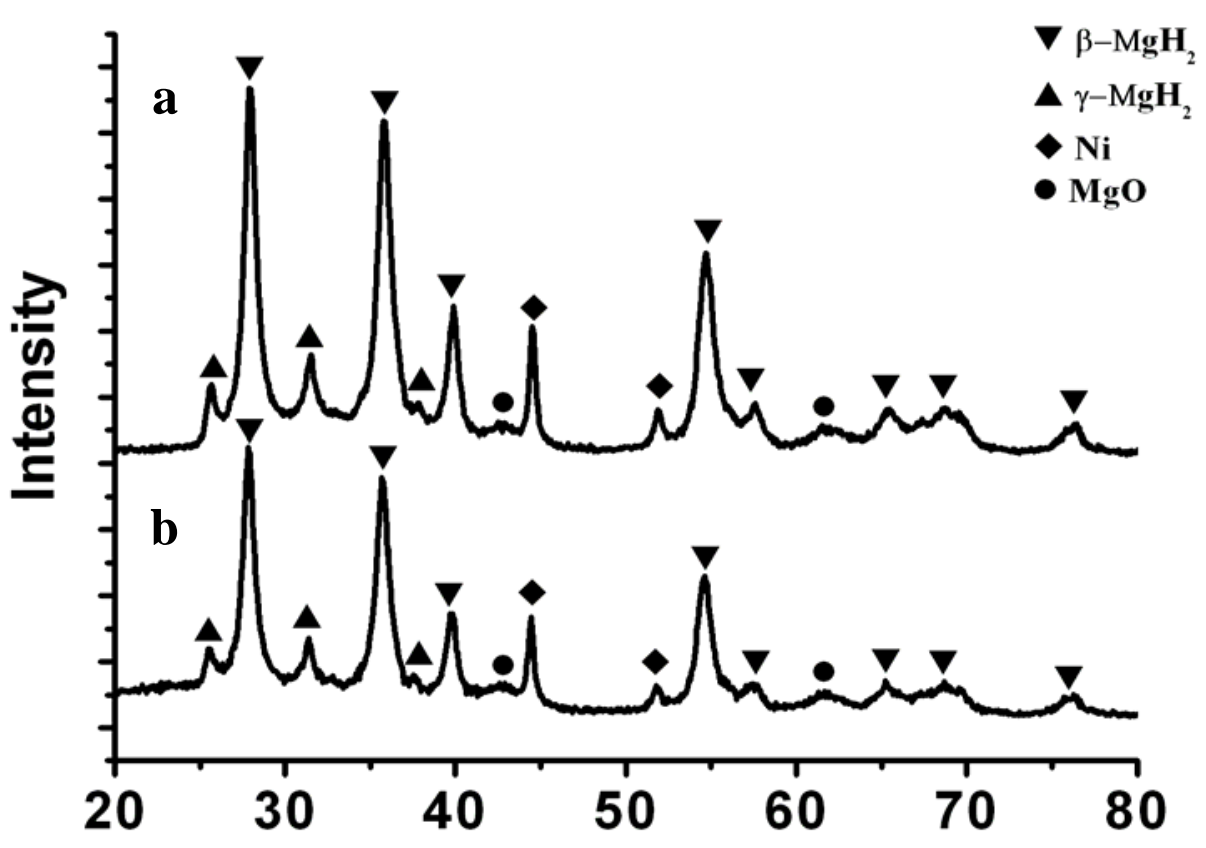

Figure 23. XRD patterns of $\mathrm{MgH}_{2} / \mathrm{Ni}$ powder(a) and $\mathrm{MgH}_{2} / \mathrm{Ni}$-aerogel(b) 


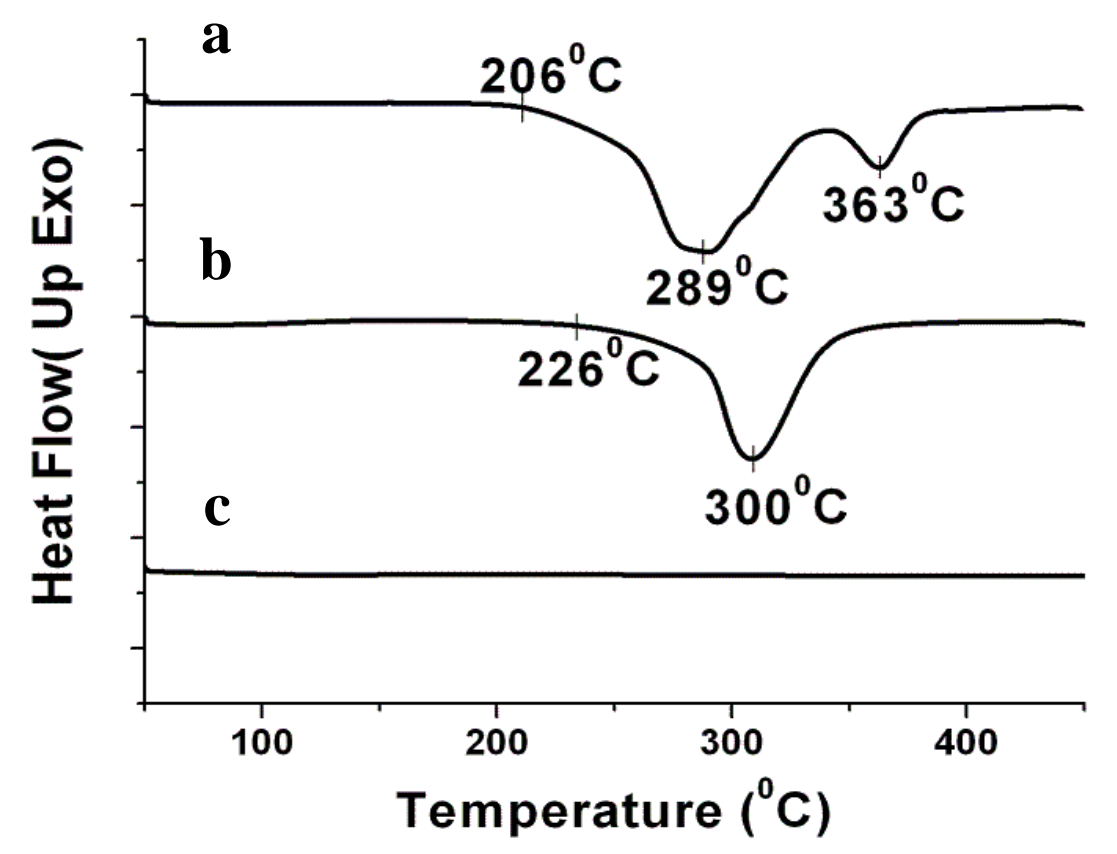

Figure 24. DSC profiles for $\mathrm{MgH}_{2} / \mathrm{Ni}$ milled powder(a) and $\mathrm{MgH}_{2} / \mathrm{Ni}$-aerogel(b), and $\mathrm{TiO}_{2}$-aerogel (c).

resulting from ball milling. While, the $\mathrm{MgH}_{2}$-aerogel composite has a temperature shift of 10 to $20{ }^{\circ} \mathrm{C}$ compared to the pure milled powder, which could be attributed to its lower thermal conductivity rather than the pure power. It is interesting to note that hydrogen was released at an onset temperature of $226^{\circ} \mathrm{C}$ and the desorption was completed by $345^{\circ} \mathrm{C}$. We speculate that the disappearance of the second hump in the composite sample is due to the uniformity of the composite porous structure. In the composite porous structure, heat is imparted uniformly to all embedded $\mathrm{MgH}_{2}$ particles, while in the ball milled $\mathrm{MgH}_{2}$ powder the finer particles are heated up more quickly and the bimodal size distribution results in two humps of heat flux intensity. Furthermore, the smooth and single-peak heat flux intensity during hydrogen desorption in the aerogel- $\mathrm{MgH}_{2}$ composite demonstrates that there is no reaction between $\mathrm{MgH}_{2}$ and the matrix, the silica.

To investigate the thermal stability of aerogel scaffold, we synthesized a second kind of aerogel composite: we embedded an inactive and thermal stable oxide, $\mathrm{a} \mathrm{TiO}_{2}$ powder in silica aerogel using the same synthesis procedure as described above. From the results shown in Fig 24(c), it can be seen that the oxide embedded aerogel exhibited stable thermal properties during the heating process.

For the investigation on the hydrogen storage capacity of $\mathrm{MgH} 2 / \mathrm{Ni}$-aerogel , the composite was measured using TGA shown in Fig. 25. TGA analysis was conducted with $\mathrm{TiO}_{2}$-aerogel as a baseline. It can be seen that the $\mathrm{MgH}_{2} / \mathrm{Ni}$ aerogel composite has a total of $4.5 \mathrm{wt} \%$ weight loss, while the $\mathrm{TiO}_{2}$-aerogel sample has a $0.5 \mathrm{wt} \%$ weight loss until $350^{\circ} \mathrm{C}$. Since the $\mathrm{TiO}_{2}$-aerogel has very stable thermal behavior as shown in Fig. 24(c), its weight loss during heating is from some chain side groups such as $-\mathrm{OH}$ and $-\mathrm{OCH}_{3}$ [30]. As the $\mathrm{MgH}_{2}$-aerogel and the $\mathrm{TiO}_{2}$-aerogel materials were synthesized under the same condition with the same amount (weight) of solids 

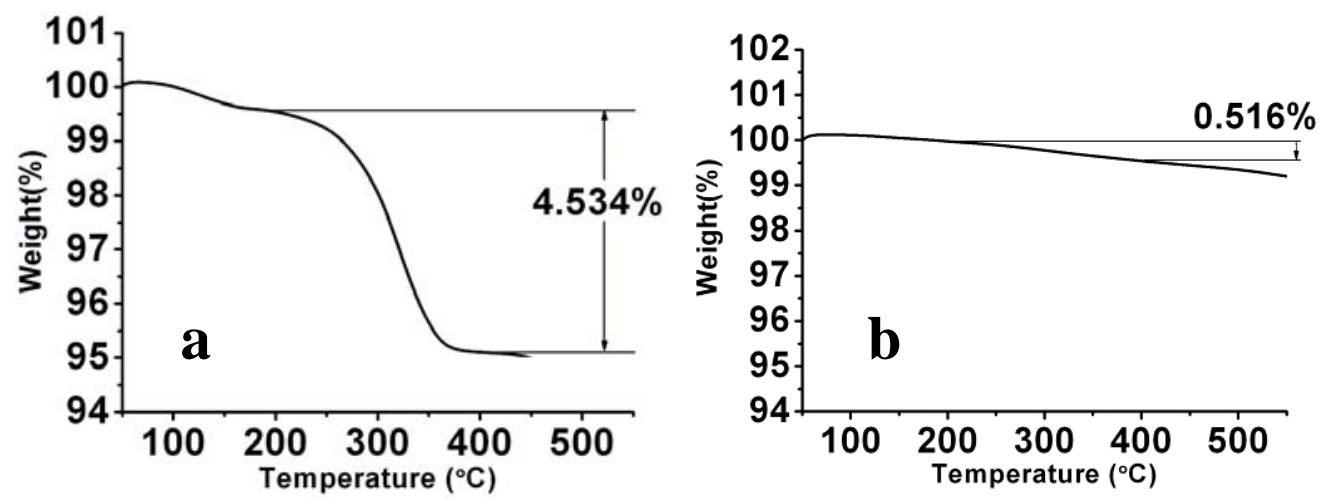

Figure 25. TGA profiles for the hydrogen desorption of $\mathrm{MgH}_{2} / \mathrm{Ni}$-aerogel (a), and $\mathrm{TiO}_{2}$-aerogel(b)

$\left(\mathrm{MgH}_{2}\right.$ and $\left.\mathrm{TiO}_{2}\right)$, we conclude that the net weight loss or hydrogen desorption until $345^{\circ} \mathrm{C}$ is $4 \mathrm{wt} \%$.

In conclusion, we established a simple hydride embedded sol-gel synthesis (Hydride SolGel) for $\mathrm{MgH}_{2} / \mathrm{Ni}$-aerogel composite. The $\mathrm{MgH}_{2}$ particles remained intact in the composite. An onset hydrogen desorption temperature of $226^{\circ} \mathrm{C}$ temperature was observed, and up to $4 \mathrm{wt} \% \mathrm{H}_{2}$ capacity was obtained for a releasing temperature below $345^{\circ} \mathrm{C}$ at ambient pressure. Furthermore, when the pore size of the aerogel composite is tuned to below several nanometers, it is anticipated that hydrogen physisorption could contribute significantly and thus both chemisorption and physisorption are combined and realized in one material [31] 


\section{Theoretical Modeling}

Metal and complex hydrides offer very promising prospects for hydrogen storage to reach the DOE targets. However, slow sorption kinetics and high release temperature must be addressed to make automotive applications feasible. It has been shown that reducing ${ }^{1}$ the enthalpy of formation of the metal hydride could positively impact the four bottlenecks mentioned above by reducing the energy barrier associated with the release of hydrogen [32]. Nanotechnology offers new ways to reduce the enthalpy of formation of metal hydrides by taking advantage of the distinctive chemical and physical properties available in nanostructures [33-35]. Increased surface and grain boundary energy could play a role in reducing the enthalpy of formation, but the predicted magnitude is too small to account for experimental observations. As the particle and grain sizes are reduced considerably, structural defects and deformations are introduced. These regions can be characterized by an excess volume (Figure 26) due to deformations in the lattice structure, and have a significant effect on the material properties of the hydride. We use two thermodynamic models to characterize the excess energy present in the deformed regions. The equations of state (EOS) provided by the models are used to explain the change in physical properties of metal hydrides. The EOSs are compared to density functional theory calculations at zero temperature for $\mathrm{Mg}$ and $\mathrm{MgH}_{2}$ to determine the range of excess volume over which they accurately predict the energy change.
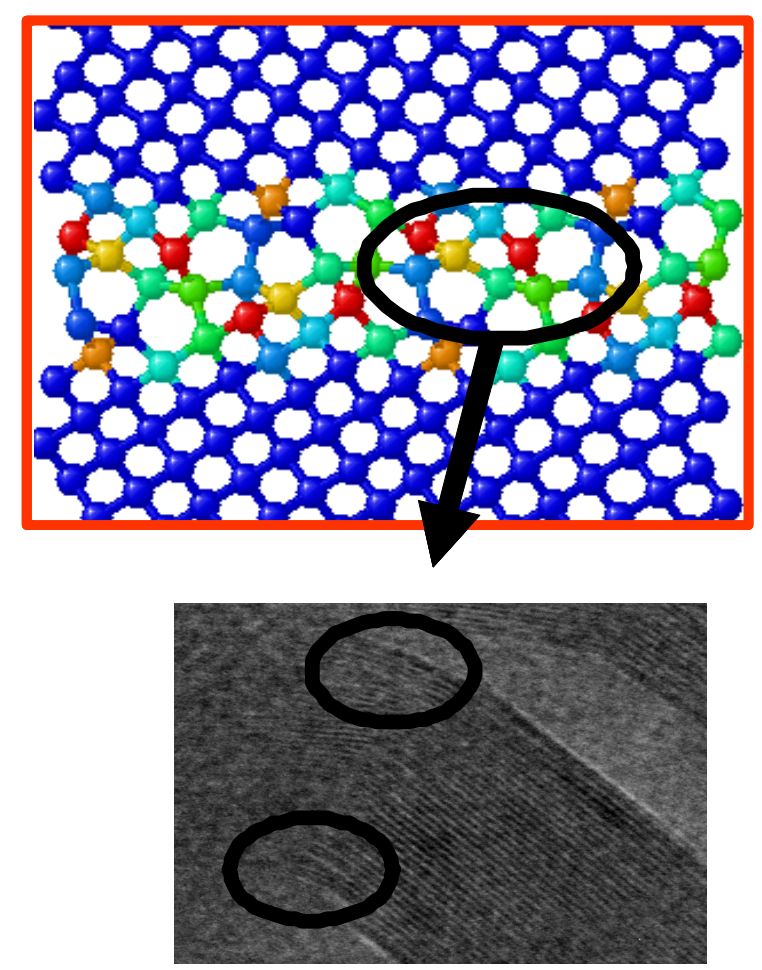

Figure 26. A schematic illustration of excess volume and a TEM image showing the possible location where excess volume is generated (e.g., at the grain boundaries).

\footnotetext{
1 The enthalpy of formation of most hydrides is negative because the reaction is exothermic. By reduction of the enthalpy of formation we refer to a reduction of the magnitude of the enthalpy that results in a destabilization of the hydride.
} 


\subsection{Surface Area}

A decreased particle size leads to an increased surface to volume ratio. Creating surfaces has an energy cost that will ultimately reduce the enthalpy of formation of the system if the surface energy of the hydrided phase is higher than that of the non-hydrided phase. Compared to the large enthalpy of formation for metal hydrides $\left(75 \mathrm{~kJ} / \mathrm{mol}\right.$ for $\mathrm{MgH}_{2}$, for example), the surface energies are usually negligible. However, for particles of sufficiently small size, the surface energy term cannot be ignored, and the molar free energy of reaction then becomes:

$$
\Delta G(r)=\Delta G_{0}(r)+R T \ln \left(\frac{a_{\mathrm{MH}_{2}}}{a_{\mathrm{M}} P_{\mathrm{H}_{2}}}\right)+\frac{3 V_{\mathrm{M}} \Delta_{\mathrm{M} \rightarrow \mathrm{MH}_{2}}(\gamma, r)}{r}
$$

where $r$ is the radius of a spherical particle and the volume-adjusted surface energy difference is [32]

$$
\Delta_{{\mathrm{M} \rightarrow \mathrm{MH}_{2}}}(\gamma, r)=\left[\gamma_{\mathrm{MH}_{2}}(r)\left(\frac{V_{\mathrm{MH}_{2}}}{V_{\mathrm{M}}}\right)^{2 / 3}-\gamma_{\mathrm{M}}(r)\right]
$$

Here, $V_{i}$ denotes the molar volume of each phase (subscript $M$ refers to the metal and $\mathrm{MH}_{2}$ refers to the metal hydride) that accommodates the $10-30 \%$ volume increase that is usually observed in metal hydrides upon hydriding, $\gamma$ is the surface energy of each phase, $a_{i}$ is the activity coefficient of the phases [32] and $P$ is the pressure of the gas.

Inclusion of the surface energy terms gives a new van't Hoff relation $(3,4)$, showing that size reduction lowers the enthalpy of hydride formation $\left(\Delta H^{\prime}\right)$ for the nanostructured hydride as long as $\Delta_{\mathrm{M}_{\mathrm{MH}}}$ is positive. As seen in Eq. (2), $\Delta_{\mathrm{M} \rightarrow \mathrm{MH}_{2}}$ will be positive if the surface tension of the hydride is larger than that of the metal since a volume expansion usually accompanies the hydriding reaction:

$$
\begin{gathered}
\ln P_{\mathrm{H}_{2}}^{e q}=\frac{\Delta H^{\prime}}{R T}-\frac{\Delta S_{0}}{R} \\
\Delta H^{\prime}=\Delta H_{0}+\frac{3 V_{\mathrm{M}} \Delta_{\mathrm{M} \rightarrow \mathrm{MH}_{2}}}{r}
\end{gathered}
$$

where $\Delta H_{0}$ is a negative quantity corresponding to the enthalpy of formation of the crystalline hydride at standard pressure and temperature [32]. In the case of $\mathrm{Mg}$, the bulk value of $1.76 \mathrm{~J} / \mathrm{m}^{2}$ [36] for $\Delta_{\mathrm{M} \rightarrow \mathrm{MH}_{2}}$ predicts that $\Delta H^{\prime}$ could be $10 \%$ smaller than $\Delta H_{0}$ for hydride particles with radii smaller than $4 \mathrm{~nm}$. Unfortunately, it would be hard to implement this sizedependent effect in $\mathrm{Mg}$ because of the limitation on the nanoparticle size that can be achieved. Calculations based on the repulsive energy between dislocations predict that a minimum particle radius size of $15 \mathrm{~nm}$ is achievable through ball milling for $\mathrm{Mg}$ [37]. At this size, the reduction in the enthalpy of formation predicted by Eq. (4) would only represent a $2-3 \%$ reduction in the enthalpy of formation of the hydride. This means that the additional surface energy created in nanopowders cannot explain the reduction of the enthalpy of formation observed in some experiments (above $20 \%$ in for $\mathrm{MgH}_{2}$ in [38]) and that other mechanisms must be responsible for the large magnitude of the enthalpy reduction. 


\subsection{Grain Boundaries}

High-energy mechanical treatments like ball milling also reduce the grain size of polycrystalline materials and introduce many grain boundaries. These grain boundaries are the result of mismatched crystal plane orientations and give rise to excess energy that in turn lead to an excess enthalpy using an approach similar to that found in Eqs. (1-4). A simple estimate of the maximum contribution of grain boundary can be obtained by equating the grain boundary energy difference to the surface energy difference between the metal hydrides and the metal, and by assuming that all grains have the smallest grain size in the sample (7-9nm for the samples we consider in the relevant experimental study [38]). This naturally overestimates the contribution since a grain boundary has a lower energy than the two surfaces creating it, due to the binding between the two planes. But the estimate thus made still provides an order of magnitude estimate for the enthalpy change. As in the case of the surface energy, the potential contribution to the enthalpy reduction is strongly limited by the relatively weak energies involved for grain boundaries (of the order of $1 \mathrm{~J} / \mathrm{m}^{2}$ as shown in Figure 29) compared to those of hydride formation: our calculation for $\mathrm{MgH}_{2}$ shows a maximum reduction in the enthalpy of formation of only $3 \%$ for a grain size of the order of $10 \mathrm{~nm}$. Those calculations were performed using experimental data from [38] where the smallest grain size measured was $8 \mathrm{~nm}$.

\subsection{Excess Volume in Deformed Regions}

The surface energy and grain boundary energy in nanostructured metal hydrides favor a reduction of the enthalpy of formation, although their combined contribution, at least for the $\mathrm{MgH}_{2}$ example, is insufficient to explain the experimental observations [38]. Another mechanism must therefore be responsible for the observed reduction in the enthalpy of formation of certain metal hydrides. In heavily milled metal hydride samples, it is likely that noncrystalline regions will arise where the material is deformed. The resulting lattice distortions will change the energy content of the metal and hydride states and therefore could explain why the enthalpy of formation is changed, as discussed below.

A simple yet accurate way to explain the effect of lattice distortions on the energy of the crystal is by formulating an equation of state (EOS) that relates the energy of the crystal to its actual volume relative to the equilibrium volume. A dimensionless excess volume $V_{\text {exc }}$ (defined as the ratio of the actual volume to the equilibrium volume) in deformed regions of metallic nanoparticles due to their longer atomic bonds was demonstrated to result in an excess energy, which can be related to a hydrostatic pressure that scales up with the atomic volume $v[39,40]$ :

$$
p(V)=\frac{3 B_{0}\left[\left(\frac{v}{v_{0}}\right)^{1 / 3}-1\right]}{\left(\frac{v}{v_{0}}\right)^{2 / 3}} \exp \left[-a_{*}\left(1-0.15 a_{*}+a_{*}^{2}\right)\right]
$$

Here $B_{0}$ is the bulk modulus, $v_{0}$ is the equilibrium atomic volume and $a_{*}$ is a scaling parameter for the excess energy specific to each material [41]. From this equation of state (Eq. (5)), the excess energy, enthalpy, entropy, and change in specific heat can be obtained from the usual thermodynamic relations. The excess enthalpy associated with the excess volume results in a reduction of the enthalpy of formation during hydrogenation if the non-hydrogenated phase has a 
smaller enthalpy increase. This can be understood from the fact that the enthalpy of formation is the difference between the enthalpy of the metal hydride and the enthalpy of the metal and the hydrogen gas together. If the enthalpy content of the metal is increased more than that of the metal hydride then the difference between the two enthalpies will increased instead of being reduced.

Another simple model that can explain how the excess volume in deformations can lead to a reduction of the enthalpy of formation in non-metallic materials is the Birch-Murnaghan (BM) equations of state that give the molar energy $E$ as a function of the equilibrium molar energy $E_{0}$, the equilibrium molar volume $V_{0}$, the actual molar volume $V$, and the bulk modulus at equilibrium $B_{0}$ [41]. At $0 \mathrm{~K}$, the enthalpy of formation coincides with the molar energy of formation between the two deformed materials.

$$
E=E_{o}+\frac{B_{o}\left(V-V_{o}\right)^{2}}{2 V_{o}}
$$

Figures 27 and 28 show a comparison between the two EOSs for $\mathrm{MgH}_{2}$ and $\mathrm{TiH}_{2}$. For $\mathrm{MgH}_{2}$, both equations of state (Eqs. (5) and (6)) predict that an excess volume will lead to a substantial reduction of the enthalpy of formation. In the case of $\mathrm{TiH}_{2}$, the bulk modulus of the hydrided phase is substantially smaller than that of titanium alone. This example shows that the hydride phase is less destabilized than the metal alone, which leads to an increase in the enthalpy of formation. A simple argument is thus capable of predicting which materials are favored by the presence of excess volume, namely that $\mathrm{MgH}_{2}$ is favored and that $\mathrm{TiH}_{2}$ is not. From the simple first order Birch-Murnaghan equation of state, we see that to first approximation, an excess volume will reduce the enthalpy of formation if the following condition is satisfied (see table 1).

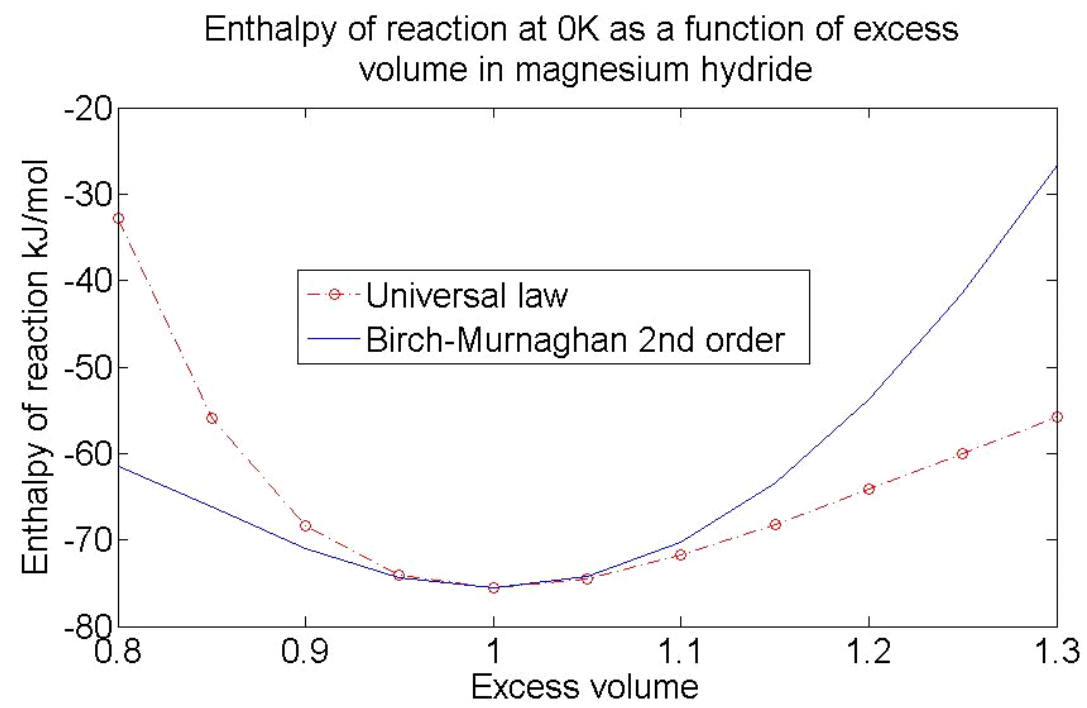

Figure 27. Predicted enthalpy of formation of $\mathrm{MgH}_{2}$ as a function of the excess volume according to the universal law (Eq. (5)) and the Birch-Murnaghan $2^{\text {nd }}$ order equation (Eq. (6) can be modified to include the change of the bulk modulus with regard to pressure. Incorporating this change leads to the Birch-Murnaghan $2^{\text {nd }}$ order equation). Even if the two EOSs do not agree on the magnitude of the change of enthalpy, they both predict a reduction of the enthalpy of formation and the magnitude of the reduction in both cases is large enough to explain experimental data (see Figure 3). Future work using density functional theory will investigate the difference between the two EOSs. 


$$
\eta=V_{o}^{M H_{2}} B_{o}^{M H_{2}}-V_{o}^{M} B_{o}^{M} \geq 0 .
$$

In Eq. (7), $\eta$ gives an idea of the degree of destabilization of a hydride with respect to its metallic phase. A large positive $\eta$ is favorable while a negative $\eta$ indicates that the presence of highly deformed regions in the sample should be avoided for hydrogen storage applications.

Table 1. Comparison of the destabilization parameter for different metal hydrides. A large positive value of $\eta$ indicates that the enthalpy of formation of the hydride is reduced by the introduction of deformed regions while a negative value shows that introducing regions of excess volume would increase the heat released upon the hydriding reaction (My screen display of the table is messed up, please check yours)

\begin{tabular}{cc}
\hline Material & $\eta[\mathbf{k J} / \mathbf{m o l}]$ \\
\hline $\mathrm{Mg} / \mathrm{MgH}_{2}$ & 805 \\
\hline $\mathrm{Li} / \mathrm{LiH}$ & 1330 \\
\hline $\mathrm{Ti} / \mathrm{TiH}_{2}$ & -2270 \\
\hline
\end{tabular}

A difference in the value of the excess volume will have a dramatic influence on the enthalpy of formation of the destabilized hydride. The fraction of the sample that is in a state of excess volume also has an important effect on the enthalpy reduction. The excess volume and the excess volume fraction will vary from sample to sample and even within distinct regions in the same sample. This is why a microscopic study of hydride samples in which enthalpy reductions have been observed is necessary to fit the theoretical models and to determine if crystal deformations can be responsible for the reduction in the enthalpy of formation. This can be done by investigating the crystal structure of heavily milled materials with a TEM to determine the concentration of extended regions and determine if any appreciable excess volume is present.

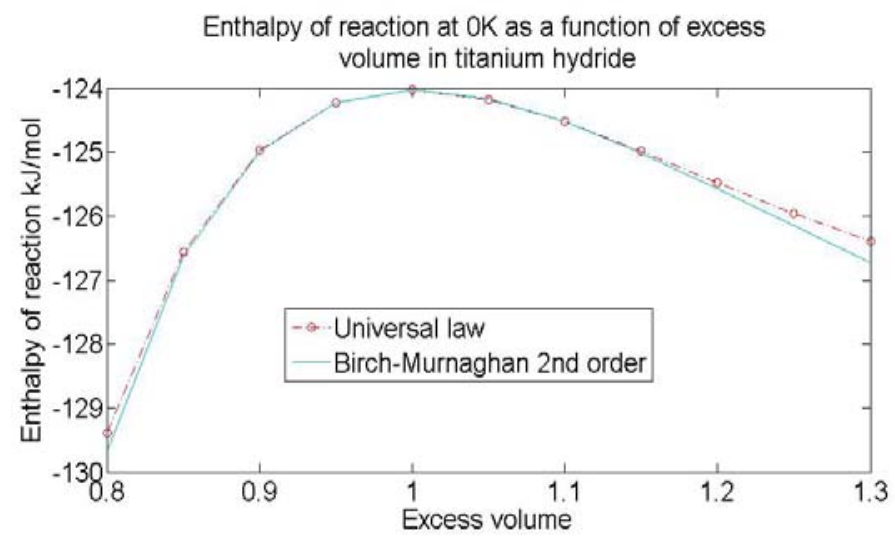

Figure 28. Predicted enthalpy of formation of $\mathrm{TiH}_{2}$ from $\mathrm{Ti}+\mathrm{H}_{2}$ as a function of the excess volume according to the universal law and the Birch-Murnaghan $2^{\text {nd }}$ order equation. The effect leads to an increase in enthalpy of formation for $\mathrm{TiH}_{2}$ when such regions are introduced. The Ti hydriding reaction illustrates the fact that not all materials will benefit from the introduction of high energy structural defects (Eq. (7) and Table 1). 
Figure 29 shows the enthalpy reduction experimentally observed in three different powders made with $\mathrm{MgH}_{2}$ nanoparticles [38]. It also shows the relative importance of the three different nanostructures studied in this paper. It is clear from the data that the particle size and size distribution are not enough to predict the enthalpy of formation and that deformed regions with excess enthalpy can explain the experimental observation. Figure 29 also illustrates that surface and grain boundary effects do not reduce the enthalpy sufficiently and that the excess volume effect is needed to explain the observed reduction in the enthalpy of formation.

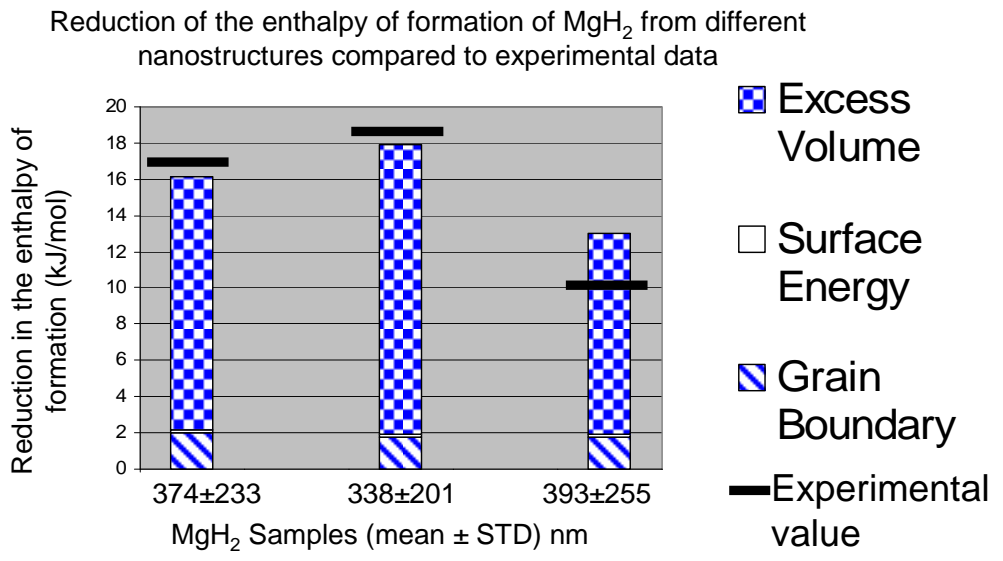

Figure 29. Comparison of the reduction of the enthalpy of formation in $\mathrm{MgH}_{2}$ predicted by the three mechanisms presented in this paper with the experimental data obtained by Varin [38] (listed as black lines). Each column represents a different size distribution of nanoparticles obtained by high energy ball milling (see [38] for more details on the exact process used to produce the particles). Calculations show that surface energy and the grain boundary energy can't explain the observed values of enthalpy. The presence of deformed regions containing excess volume, on the other hand, can account for the order of magnitude reduction in the enthalpy of formation seen experimentally. For the calculations plotted on this graph, we chose a dimensionless excess volume $V_{\text {exc }}$ of 1.3 over $35 \%$ of the sample.

\subsection{Conclusions}

Metal hydrides possess high storage capacity but there remain many issues that must be addressed before automotive applications are feasible. These are:

1. Slow sorption kinetics

2. High hydrogen release temperature

3. Low storage efficiency

4. Thermal management

Reducing the enthalpy of formation through the introduction of nanostructures is a strategy to address these issues because it reduces the energy barrier for hydrogen release. That in turns reduces the temperature needed for hydrogen extraction which indirectly addresses the other bottlenecks mentioned above. The introduction of surfaces and grain boundaries can lead to a reduction of the enthalpy of formation of a few percent, but cannot explain the experimental observations where reductions of more then $20 \%$ have been observed [38]. Only when considering the presence of deformed regions with excess volume were we able to reproduce the experimental data. 


\section{References}

1. N. Bazzanella, R. Checchetto, A. Miotello, C. Sada, P. Mazzoldi, P. Mengucci, Appl. Phs. Lett. 89 (2006) 014101.

2. F. Zeppelin, H. Reule, M. Hirscher, J. Alloys Compd. 330-332 (2002) 723-726.

3. L. Berlouis, P. Honnor, P. Hall, S. Morris, S. Dodd, J. Mater. Sci. 41 (2006) 6403-6408.

4. A. Bassetti, E. Bonetti, L. Pasquinin, A. Montone, J. Grbovic, M. Antisari, Eur. Phy. J. B 43 (2005) 19-27.

5. J. Ryden, B. Hjorvarsson, T. Ericsson, E. Karlsson, A. Krozer, B. Kasemo, J. Less-Common Met. 152 (1989) 295-309.

6. K. Yoshimura, Y. Yamada, M. Okada, Surf Sci 566-588 (2004) 751-754..

7. A. Leon, E. Knystautas, J. Huot, R. Schulz, J. Alloys Compd. 345 (2002) 158-166.

8. T. Richardson, J. Slack, R. Armitage, R. Kostecki, B. Farangis, M. Rubin, Appl. Phys. Lett. 78 (2001) 3047-3049.

9. T. Richardson, J. Slack, B. Farangis, M. Rubin, Appl. Phys. Lett. 80 (2002) 1349-1351.

10. R.J. Westerwaal, A. Borgschulte, W. Lohstroh, B. Dam, B. Kooi, G. Ten Brink, M.J.P. Hopstaken, P.H.L. Notten, J Alloys Compd. 416 (2006) 2-10.

11. A. Zaluska, L. Zaluski and J.O. Ström-Olsen, J. Alloys Compd. 288 (1999) 217-225.

12. G. Libowitz, A. Maeland, J. Less-Common Met 101 (1984) 131-143.

13. Y. Shan, F. Spaepen, D. Turnbull, Metall Mater. Trans. A. 29A (1998) 1825-1828.

14. F. Spit, J. Drijver, S. Radelarr, Scripta Metallurgica 14 (1980) 1071-1076.

15. D. Ryan, F. Dumais, B. Patel, J. Kycia, J. Strom-Olsen, J. Less-Common Met. 172-174 (1991) 12461251.

16. A. Krozer, B. Kasemo, J. Less-Common Met 160 (1990) 323-342.

17. K. Higuchi, K. Yamamoto, H. Kajioka, K.Toiyama, M. Honda, S. Orimo, H.Fujii, J. Alloys Compd. 330-332 (2002) 526-530.

18. R. Gremaud, A. Borgschulte, W. Lohstroh, H. Schreuders, A. Zuttel, B. Dam, R. Griessen, J. Alloys and Comp. 404-406 (2005) 775.

19. R. Yu, P. Lam, Phys. Rev. B 37 (1988) 8730-8737.

20. J. Isidorsson, I. Giebels, H. Arwin, R. Griessen, Phys. Rev. B 68 (2003) 115112-1-13.

21. T.J. Richardson, Appl. Phys. Lett 78 (2001) 3047.

22. R.J. Westerwaal, J. Appl Phys 100 (2006) 063518.

23. P. M. Forster, J. Eckert, B.D. Heiken, J.B. Parise, J. W. Yoon, S. H. Jhung, J. S. Chang, A. K. Cheetham, J. Am. Chem. Soc. 128 (2006), 16846-16850.

24. S.S. Kaye, A. Dailly, O.M. Yaghi, J. R. Long, J. Am. Chem. Soc. 129 (2007), 14176-14177.

25. G. Liang, J. Huot, S. Boily, A. Van Neste, R. Schulz, J. Alloys Compd 292 (1999), 247-252.

26. J. Huot, G. Liang, S. Boily, A.Van Neste, R.Schulz, J. Alloys Compd. 293 (1999), 495-500.

27. S. Doppiu, P. Solsona, T. Spassov, G. Barkhordarian, M Dornheim, T. Klassen, S. Surĩnach, M.D. Baro, J. Alloys Compd. 404 (2005), 27-30.

28. A. Gutowska, L.Y. Li, Y.S. Shin, C.M. Wang, X. S. Li, J.C. Linehan, R.S. Smith, B.D. Kay, B. Schmid, W. Shaw, M. Gutowski, T. Autrey, Angew. Chem. Int. Ed. 44 (2005), 35783582.

29. J. Hu, M. Fichtner, P. Chen, Chem. Mater. 20 (2008), 7089-7094.

30. J. Hu, Y. Liu, G. Wu, Z. Xiong, Y. S. Chua, P. Chen, Chem. Mater. 20 (2008), 4398-4402.

31. S. Zheng, F. Fang, G. Zhou, G. Chen, L. Ouyang, M. Zhu, D. Sun, Chem. Mater. 20 (2008), 3954-3958.

32. V. Bérubé, G. Radtke, M. Dresselhaus, G. Chen. Size effects on the hydrogen storage properties of nanostructured metal hydrides: A review, Int J Energy Research, 31 (2007), 637-663. 
33. A. Zaluska, L. Zaluski, J.O. Ström-Olsen, Structure, catalysis and atomic reactions on the nano-scale: a systematic approach to metal hydrides for hydrogen storage. Applied Physics A. 72(2001), 157-165.

34. A. Zaluska, L. Zaluski, J.O. Strom-Olsen. Nanocrystalline magnesium for hydrogen storage. Journal of Alloys and Compounds. 288(1999), 217-225.

35. L. Zaluski, A. Zaluska, J.O. Strom-Olsen. Nanocrystalline metal hydrides. Journal of Alloys and Compounds. 253-254(1997), 70-79.

36. K. Johnson and B. Dai, at the University of Pittsburgh (private communication).

37. J. Eckert,. Relationships governing the grain size of nanocrystalline metals and alloys. Nanostructured Materials. 6(1995), 413-416.

38. R.A. Varin, T. Czujko, C.H. Chiuand Z. Wronski, Particle size effects on the desorption properties of nanostructured magnesium dihydride $\left(\mathrm{MgH}_{2}\right)$ synthesized by controlled reactive mechanical milling (CRMM), J. Amer. Chem. Soc. 424 (2006):356-364.

39. D. Wolf, Correlation between the energy and structure of grain boundaries in b.c.c metals. I. Symmetrical boundaries on the (110) and (100) planes. Philosophical Magazine B. 59(1989), 667-680.

40. J. Ferrante, J. R..Smith, Theory of the bimetallic interface. Physical Review B. 31(1985), 3427-3434.

41. F. D. Murnaghan, The Compressibility of Media under Extreme Pressures. Proceedings of the National Academy of Sciences. 30 (1944), 244-247. 


\section{List of Publications Attributable to the Grant}

Journal Publications

1. V. Bérubé, G. Radtke, M. Dresselhaus, G. Chen, "Size effects on the hydrogen storage properties of nanostructured metal hydrides: A review", Int. J. Energy Research, 31, 637, 2007.

2. V. Bérubé, M. Dresselhaus, G. Chen, "Temperature dependence of the enthalpy of formation of metal hydrides characterized by an excess volume. Int. J. Hydrogen Energy", 33, 56175628, 2008.

3. V. Bérubé, M. Dresselhaus, G. Chen, "Impact of nanostructuring on the enthalpy of formation of metal hydrides", Int. J. Hydrogen Energy, 33, 4122-4231, 2008.

4. V. Bérubé, M. Dresselhaus, G. Chen, Entropy stabilization of deformed regions characterized by an excess volume for hydrogen storage applications, Int. J. Hydrogen Energy, 34,1862-1872, 2009.

5. S. S. Mao and X. Chen, "Selected nanotechnologies for renewable energy applications", Int. J. Energy Research, 31, 619, 2007.

6. M. Rogers, X. Chen, T. J. Richardson, V. Berube, G. Chen, M. S. Dresselhaus, C. P. Grigoropoulos, S. S. Mao, "Hydrogen storage characteristics of nano-grained free-standing magnesium-nickel films", Applied Physics A, 96, 349-352, 2009

7. Y. Zuo, Y. He, C. Wu, S. S. Mao, C. Koch, T. Zeng, "MgH2-Aerogel Composite for Hydrogen Storage," J. Alloy and Compounds, Submitted, 2009.

8. C. Wu, B. P. Mosher, and T. Zeng, "Chemically-Mechanically Assisted Synthesis of Metallic and Oxide Nanoparticles in Ambient Conditions", Journal of Nanoscience and Nanotechnology, vol. 8, pp.386-389, 2008.

9. C. Wu and T. Zeng, "Size-Tunable Synthesis of Metallic Nanoparticles in a Continuous and Steady-Flow Reactor", Chemistry of Materials, vol. 19, pp. 123-125, 2007.

10. C. Wu, B. P. Mosher, and T. Zeng, "Rapid Synthesis of Gold and Platinum Nanoparticles Using Metal Displacement Reduction with Sonomechanical Assistance", Chemistry of Materials, vol. 18, pp. 2925-2928, 2006.

Conference Presentations

1. V. Bérubé, M. Dresselhaus, G. Chen, M. Rogers, C. P. Grigoropoulos, S. S. Mao, Julius Springer Applied Physics Forum, Cambridge, MA, September, 2008.

2. S. S. Mao, National Academy of Engineering Frontiers of Engineering (GAFOE) Symposium, Irvine, CA, April, 2008.

3. Y. Zuo, C. Wu, S. S. Mao, and T. Zeng, "Aerogel Composite for Hydrogen Storage”, MRS, Symposium S: Materials and Technology for Hydrogen Storage, November, 2007.

4. B. P. Mosher, C. Wu, S. Mao, G. Chen, and T. Zeng, In Depth Investigation of Hydrogen Storage and Absorption/Release Kinetics in Metal Ammine Complexes and Nanoscaffolds, Presented at MRS (Material Research Society) Spring Meeting, San Francisco, April, 2006. 


\section{List of People Supported by the Project}

MIT:

Vincent Berube, PhD student, now at McKinsey

Greg Radtke, PhD student

Dr. Xiaoyuan Chen, Research scientist

UC-Berkeley:

S. Barcelo, PhD student

X.B. Chen, Post doctor

M. Roger, PhD student

K.R. Carrington, PhD student

Intematix:

X. Shen, Engineer

NC State:

Brian P. Mosher, MS student

Yanjia Zuo, MS student

Chunwei $\mathrm{Wu}, \mathrm{PhD}$ student and post doctor 